\title{
Nanotechnology Based Approaches in Phage Therapy: Overcoming the Pharmacological Barriers
}

\author{
Sandeep Kaur ${ }^{1}$, Anila Kumari ${ }^{1}$, Anjana Kumari Negi ${ }^{2}$, Vikas Galav ${ }^{3}$, Shikha Thakur ${ }^{4}$, \\ Manish Agrawal $^{3}$ and Vandana Sharma ${ }^{1 *}$ \\ ${ }^{1}$ Department of Food Science, Mehr Chand Mahajan DAV College for Women, Chandigarh, India, ${ }^{2}$ Department of Biochemistry, \\ Dr. Rajendra Prasad Government Medical College, Himachal Pradesh, India, ${ }^{3}$ Department of Veterinary Pathology, Post Graduate \\ Institute of Veterinary Education and Research (RAJUVAS), Jaipur, India, ${ }^{4}$ Department of Biotechnology, Kumaun University, \\ Uttarakhand, India
}

OPEN ACCESS

Edited by:

Mayank Gangwar,

Banaras Hindu University, India

Reviewed by:

Shilpa Deshpande Kaistha, Chhatrapati Shahu Ji Maharaj

University, India

Ramesh Nachimuthu, VIT University, India

*Correspondence:

Vandana Sharma

vandanamcm5@gmail.com

Specialty section: This article was submitted to Translational Pharmacology,

a section of the journal

Frontiers in Pharmacology

Received: 22 April 2021

Accepted: 26 July 2021

Published: 05 October 2021

Citation:

Kaur S, Kumari A, Kumari Negi A, Galav V, Thakur S, Agrawal M and

Sharma V (2021) Nanotechnology Based Approaches in Phage Therapy:

Overcoming the

Pharmacological Barriers.

Front. Pharmacol. 12:699054. doi: 10.3389/fphar.2021.699054
With the emergence and spread of global antibiotic resistance and the need for searching safer alternatives, there has been resurgence in exploring the use of bacteriophages in the treatment of bacterial infections referred as phage therapy. Although modern phage therapy has come a long way as demonstrated by numerous efficacy studies but the fact remains that till date, phage therapy has not received regulatory approval for human use (except for compassionate use). Thus, to hit the clinical market, the roadblocks need to be seriously addressed and gaps mended with modern solution based technologies. Nanotechnology represents one such ideal and powerful tool for overcoming the pharmacological barriers (low stability, poor in-vivo retention, targeted delivery, neutralisation by immune system etc.) of administered phage preparations.In literature, there are many review articles on nanotechnology and bacteriophages but these are primarily focussed on highlighting the use of lytic and temperate phages in different fields of nano-medicine such as nanoprobes, nanosensors, cancer diagnostics, cancer cell targeting, drug delivery through phage receptors, phage display etc. Reviews specifically focused on the use of nanotechnology driven techniques strictly to improve phage therapy are however limited. Moreover, these review if present have primarily focussed on discussing encapsulation as a primary method for improving the stability and retention of phage(s) in the body. With new advances made in the field of nanotechnology, approaches extend from mere encapsulation to recently adopted newer strategies. The present review gives a detailed insight into the more recent strategies which include 1) use of lipid based nano-carriers (liposomes, transfersomes etc.) 2) adopting microfluidic based approach, surface modification methods to further enhance the efficiency and stability of phage loaded liposomes 3) Nano- emulsification approach with integration of microfluidics for producing multiple emulsions (suitable for phage cocktails) with unique control over size, shape and drop morphology 4) Phage loaded nanofibers produced by electrospinning and advanced core shell nanofibers for immediate, biphasic and delayed release systems and 5) Smart release drug delivery platforms that allow superior control over dosing and phage release as and when required. All these new advances are aimed at creating a suitable housing system for therapeutic bacteriophage preparations while targeting the multiple issues of phage therapy i.e., improving phage stability and titers, 
improving in-vivo retention times, acting as suitable delivery systems for sustained release at target site of infection, improved penetration into biofilms and protection from immune cell attack. The present review thus aims at giving a complete insight into the recent advances (2010 onwards) related to various nanotechnology based approaches to address the issues pertaining to phage therapy. This is essential for improving the overall therapeutic index and success of phage therapy for future clinical approval.

Keywords: nanotechnology, phage therapy, nano-emulsification, encapsulation, liposome, nanofibers, pharmacological barriers

\section{INTRODUCTION}

Phages are ubiquitous in nature representing the most abundant organisms in our ecosystem playing an important part in regulation and development of microbial communities (Clokie et al., 2011; Sharma et al., 2017). Like their host bacteria, phages have been exploited by the research community in many different fields ranging from phage display, cancer cell targeting, drug delivery, diagnostic applications, gene delivery, and nanoprobes etc. (Harada et al., 2018). One of the important properties of phages that had been explored long back but has showed a renewed interest is "Phage Therapy" i.e., the application of lytic phages against pathogenic bacteria leading to their lysis and final killing (Sulakvelidze et al., 2001; Lin et al., 2017). This application of phages also called phagotherapy represents a potential antibacterial strategy worth exploring and the reasons are many fold. The primary and the strongest reason is the need to develop methods to fight the battle against rising antibiotic resistance. Overuse and misuse of antibiotics globally has led to the emergence and spread of Antimicrobial resistance, 2020 (AMR) as we are stepping close to the threat of entering the post-antibiotic era (Zucca and Savoia, 2010; Ventola et al., 2015; Taneja et al., 2019). WHO has declared AMR in the list of top 10 global public health threats facing humanity (Antimicrobial resistance, 2020).This calls for the scientific community to focus all its efforts to develop novel and promising nonantibiotic options. Phage therapy is definably a potent nonantibiotic option to curtail the relentless increase in antibioticresistant bacteria and all efforts in making this treatment enter the clinical market are prudent (Gordillo Altamirano and Barr, 2019; Brives and Pourraz, 2020). Secondly, phages are omnipresent in nature and they are natural commensals of human and animal body (Kutter and Sulakvelidze 2005; Clokie et al., 2011; Koskella and Brockhurst, 2014; Batinovic et al., 2019). Their ubiquitous nature strongly supports the fact that they are harmless entities showing no ill effects to eukaryotic cells even at high titers. Next major advantage is their high specificity and a targeted killing mechanism. Lytic phages infect their target bacterial cells after recognizing specific receptors. This specificity allows attacking target bacterial strains only further making this option a safe and gentle approach (Loc-Carillo et al., 2011; Principi et al., 2019). Besides these points, phages exhibit the property of self-dosing as they are able to replicate at the expense of host bacterium. This contributes to regulate phage numbers in direct relation with pathogen level allowing their diffusion in nearby areas till the pathogen population is present (Abedon and Thomas-Abedon, 2010; Drulis-Kawa et al., 2012).

Phage therapy has shown significant potential as highlighted by various in vitro and in vivo studies done in the past against range of bacterial infections. Results indicate that this therapy has immense potential with applications in human medicine as well as veterinary science, agriculture, and food sector. Despite this picture, the fact remains that till date, and phage therapy has not received regulatory approval for human use (except for compassionate/emergency use and in the food sector). Although phage therapy has come a long way, but there are still major loopholes and gaps that need to be addressed and worked upon with modern solution based technologies (Alvarez et al., 2019; Nilsson, 2019).

Nanotechnology is one such ideal and powerful tool for overcoming majority of the barriers associated with administered phage preparations. The present review firstly provides an overview of the major pharmacological and clinical challenges acting as major hurdles. The review then focuses on discussing in detail, the different nanotechnology based advances (extending from mere nano-encapsulation to the more recent strategies adopted) along with their mode of action in improving the pharmacological aspects and benefits thus observed. The discussion is supported by documenting recent in-vitro and in-vivo research studies done and the gaps addressed. The present review thus tends to give a comprehensive understanding into the integration and exploitation of nanotechnology based modelling in phage therapy for overcoming and optimising the pharmacokinetic profile of phage and phage products.

\section{PHARMACOLOGICAL BARRIERS IN PHAGE THERAPY: AN OVERVIEW}

Pharmacology of any administered drug can be divided into two domains: 1) pharmacokinetics and pharmacodynamics. Briefly, pharmacodynamics includes the therapeutic effects of the administered drug on the body while pharmacokinetic profile of the drug dictates its absorption, retention and clearance within the patient's body (Baggot, 1990; Palleria et al., 2013). Both these domains are inter-dependent and help to define an ideal drug and its therapeutic index and this stands true for phages as well. Looking at the pharmacokinetic aspect of phage administration, the unmet limitations are many and even more than antibiotics. 
Firstly, we need to admit the fact that phages are living entities (unlike chemical drugs) showing large variations among themselves depending on their virulence, differences in lytic infection cycle such as burst size, adsorption rate, and latent period etc. (Abedon et al., 2001; Gallet et al., 2011; Nilsson, 2019). Moreover, phages are bigger molecules in terms of size than a normal chemical drug which makes its uptake and translocation within the body more challenging and more susceptible to be easily cleared by the innate system. This makes phage pharmacokinetics fundamentally different from the normal chemical drugs (Drulis-Kawa et al., 2012; Navarro and muniesa, 2017). Second criterion which decides the therapeutic efficacy is the requirement of high titers of phage (i.e., maintenance of viability) at the target site so as to dominate over the bacterial population and control their multiplication. This is the most difficult achievable parameter as it depends on number of factors which are further linked to each other. These include: 1) route of administration, 2) target bacterial density 3) in-vivo clearance rates (clearance by immune cells, phagocytes, complement, and reticuloendothelial system), 4) inactivation of active phages (low $\mathrm{pH}$, bile, body fluids, and enzymes etc.) and 5) poor penetration and inaccessibility of phage to reach deep seated tissue areas and biofilm based infections while crossing all barriers (Payne and Jansen, 2001,2003; Levin and Bull, 2004; Dąbrowska and Abedon, 2019).

It is well known that body' impact to any drug varies with the mode of drug administration (Benet, 1978; Jin et al., 2015). Phages have been administered via many routes such as topical application, intraperitoneal (i.p), subcutaneous (s.c), intramuscular (i.m), intravenous (i.v) as well as oral delivery. For example, giving phage via injections helps to overcome body's innate defence barriers allowing the phage to rapidly reach systemic circulation showing higher therapeutic effect especially while treating immediate conditions like bacteremia or septicaemia etc. (Bogovazova et al., 1991; Chhibber et al., 2008; Jennes et al., 2017). Same way, the $i$. $p$ route is more effective in delivering high titers of phage reaching blood circulation sooner than when given via $i . m$ or $s . c$ routes (McVay et al., 2007; Takemura-Uchiyama et al., 2014). Also, directly injecting the phage to the target tissue or direct application onto the wound site seems the most favourable option as systemic circulation is further bypassed and distribution obstacles to phage movement are minimised (Beridze, 1938; Kumari et al., 2009; Chhibber et al., 2013; Yin et al., 2017; Ferry et al., 2018) However, there exist challenges regarding delivery of phages via oral route for treating enteric infections or via inhalation route in case of treating respiratory infections. Oral administration of phage is faced by major barriers as phage struggles to bear the harsh environment of the gastrointestinal tract. High stomach acidity, bile intolerance and inactivation by digestive enzymes and other proteases lead to significant drop in final titre not sufficient enough to produce the intended therapeutic effect (Young and Gill, 2015; Sarker et al., 2016; Abdelsattar et al., 2019). Similarly, as compared to $i$. p. and i. $m$. injections in animal models, inhalation has resulted in poor absorption efficacy (Carmody et al., 2010; Singla et al., 2015).
For phage therapy to be effective, the dose of phage present at the infection site must be higher than the inundation threshold (i.e., concentration of free phage required for reducing bacterial loads). For this, phage titers need to be maintained at high numbers through productive infection that is further dependant on target bacterial density as a minimal bacterial concentration (called proliferation threshold) is needed for this (Payne et al., 2000; Payne and Jansen, 2001; Abedon, 2009; Ryan et al., 2011; Abedon 2014). Further, to maximise this effect, phages need to be applied as close to site of infection where active bacterial population is high enough to bring exponential increase in phage numbers via repeated lytic cycles (Nilsson, 2014). But this is not the case with most of the routes. Thus, it becomes a major challenge to protect and maintain phage titers (as they pass across various barriers of human body) till they reach the target site.

Another challenge is the inaccessibility of phage to reach deep seated infection areas as such sites are complexed due to poor penetration and presence of dead tissue debris, necrotic cells, immune cells, tissue gluing material etc. (Dąbrowska and Abedon, 2019; Huh et al., 2019). Further, phages being small lipophilic molecules do not exhibit efficient transdermal absorption and penetration for use in deep seated skin infections (Dąbrowska, 2019).

Although phages display potent anti-biofilm ability, there does exists penetration and motion barriers through the biofilm matrix. As the biofilm matrix matures and becomes thick, its interior become less favourable to virion diffusion and maintaining active phage infection. Also, while moving, phages meet adsorbed biofilm bacteria (not the free-living ones) and such adsorbed bacteria fail to support productive phage infections (Gonzalez et al., 2018; Simmons et al., 2018). Another obstacle is the inaccessibility of phage to infect the intracellular pathogens as phage lack the ability to enter eukaryotic cells. Studies in past have shown that phages when co-infected with their target bacterium showed reduction in intracellular loads but phage alone was unable to bring the same effect (Capparrelli et al., 2007; Kaur et al., 2014) thus emphasizing on the need of an optimal phage delivery vehicle to treat such intracellular infections.

Finally, the biggest issue is phage inactivation and short halflife due to clearance from the patient's body leading to low clinical benefit. Since phages are large molecules, they are easily trapped and cleared by the mononuclear phagocyte system (MPS). Both liver and spleen are active organs of the MPS system and are responsible for phage neutralisation and early exit from the body (Abedon and Thomas-Abedon 2010; Dabrowska and Abedon, 2019). This explains that after intravenous administration, the titers rapidly drop to significantly low levels, mainly due to innate immunity and MPS clearance as noted by past researchers in different animal models (Schultz and Frohlich., 1965; Inchley, 1969; Oechslin et al., 2017). Other nonspecific factors include complement mediated clearance, inactivation by body fluid's components and enzymes etc. leading to phage inactivation and the same was observed in various studies leading to rapid loss of viable titers 
TABLE 1 | Major human trials for testing efficacy of phage therapy and reason of failures.

\begin{tabular}{|c|c|c|c|}
\hline Year & Brief details & Major limitations/findings & References \\
\hline $\begin{array}{l}\text { June } 2009 \text { to } \\
\text { September } 2011\end{array}$ & $\begin{array}{l}\text { Prospective, single center, randomized, placebo- } \\
\text { controlled trial to study the safety and efficacy of T4-like } \\
\text { phage cocktail in 6-24-month-old male children } \\
\text { presenting acute diarrhoea. }\end{array}$ & $\begin{array}{l}\text { - Oral coliphages showed a safe gut transit in children } \\
\text { - Failed to achieve intestinal amplification attributed to too } \\
\text { low E. coli pathogen titers not enough to support active } \\
\text { phage infection. } \\
\text { - Possible contribution of other pathogens such as } \\
\text { Streptococcus spp. as causative agents }\end{array}$ & Sarker et al. (2016) \\
\hline 2014 & $\begin{array}{l}\text { - Study on } 122 \text { patients at the Phage Therapy Unit in } \\
\text { Wrocław with bacterial infections to verify whether } \\
\text { phage therapy (PT) can induce anti-phage antibodies } \\
\text { when give through various routes (orally, locally, orally/ } \\
\text { locally, intrarectally, or orally/intrarectally). } \\
\text { - Anti-phage activity determined in sera from the } 122 \\
\text { patients before and during PT, and in sera from } 30 \\
\text { healthy volunteers using a neutralization test. Further, } \\
\text { levels of anti-phage antibodies determined in sera of } 19 \\
\text { patients PT and sera of } 20 \text { healthy volunteers using } \\
\text { ELISA. }\end{array}$ & $\begin{array}{l}\text { - Phage inactivation rates ( } \mathrm{K} \text { value) showed low } \mathrm{K} \text { values } \\
(\leq 1.73 \text { ) seen in sera of healthy volunteers and also low } \mathrm{K} \\
\text { value in patients before PT ( } \mathrm{K} \leq 1.64) \text {. However, in } \\
12.3 \% \text { of examined patients ( } n=15) \text {, phages given } \\
\text { locally }(n=13) \text { and phages given locally/orally }(n=2) \\
\text { showed high } \mathrm{K} \text { values in their sera i.e., } \mathrm{K}>18 \text { as } \\
\text { measured } 15-60 \text { days of PT and high phage } \\
\text { inactivation was seen especially in patients treated with } \\
\text { some } S \text {. aureus, } P \text {. aeruginosa, and } E \text {. faecalis phages } \\
\text { - Phage inactivation by sera depends on route of } \\
\text { administration and phage type. }\end{array}$ & $\begin{array}{l}\text { Łusiak-Szelachowska et al. } \\
\text { (2014) }\end{array}$ \\
\hline 2004 & $\begin{array}{l}\text { Double-blind, controlled clinical trial to evaluate the efficacy } \\
\text { and safety of a therapeutic bacteriophage preparation } \\
\text { (Biophage-PA) targeting antibiotic-resistant } P \text {. aeruginosa } \\
\text { in chronic otitis in } 24 \text { patients }\end{array}$ & $\begin{array}{l}\text { - Phage therapy showed clearing of infection but only in } 3 \\
\text { out of } 12 \text { cases while there was only a minor reduction } \\
\text { in bacterial counts in other participants indicating } \\
\text { towards use of low phage dose }\left(2 \times 10^{4} \mathrm{PFU}\right) \text { given as } \\
\text { one reason. }\end{array}$ & Wright et al. (2009) \\
\hline $\begin{array}{l}\text { July } 2015 \text { to Jan } \\
2017\end{array}$ & $\begin{array}{l}\text { Randomised, controlled, double-blind phase trial to study } \\
\text { efficacy and tolerability of a cocktail of } 12 \text { bacteriophages } \\
\text { (PP1131) to treat burn wounds infected by P. aeruginosa } \\
\text { as compared to standard of care antibiotic }\end{array}$ & $\begin{array}{l}\text { - Trial was halted prematurely due to poor efficacy of } \\
\text { phage cocktail mix compared to standard of care (SOC) } \\
\text { antibiotic. } \\
\text { - PP1131 titre decreased after manufacturing and } \\
\text { participants were given a lower concentration of phages } \\
\text { than initially expected. } \\
\text { - Ancillary study showed that the bacteria isolated from } \\
\text { patients with failed PP1131 treatment were resistant to } \\
\text { phage doses. }\end{array}$ & Jault et al. (2019) \\
\hline
\end{tabular}

(Sulkin et al., 1957; Keller and Zatzman, 1959; Majewska et al., 2015; Bichet et al., 2021).

Finally, phage neutralisation is not just due to nonspecific responses but also due to specific induction of antibody response which is subject to route of application and dosing regimen. Phage administration through local application evokes with minimal immune reaction but phages administered via systemic routes have a tendency to evoke a higher immune reaction. The presence of antibodies induced by administration of phages has been reported in animal studies (Uhr et al., 1962; Huff et al., 2002; Huff et al., 2010; Majewska et al., 2015) as well as in humans studies (Slopek et al., 1987) and these neutralising antibodies can be devastating for phage therapy especially when the treatment regimen needs recurring phage applications (Fogelman et al., 2000). With these challenges, some of the human trials did not progress to the next stage and were halted owing to failures and loopholes at one or the other front as depicted in Table 1.

Among the major pharmacodynamic limitations, purity of final phage preparation is important as it should be free from all possible impurities and endotoxin. Also, complete characterisation of the therapeutic phage along with its genome annotation is essential so as confirm that the phage in question does not encode for antibiotic resistance or toxins etc. (Philipson et al., 2018; Hyman, 2019). In addition to this, phage host range and the emergence of bacterial resistance to the administered phage are other main factors affecting the therapeutic efficacy and clinical outcome of phage therapy (Dabrowska and Abedon, 2019; Nilsson, 2019). The present review however primarily focuses on the role of nanotechnology based techniques to address most of the pharmacokinetic limitations associated with phage administration. Solutions for overcoming the pharmacodynamic challenges (such as narrow host range, resistance emergence) are presently out of the scope of this review.

\section{NANOTECHNOLOGY TO THE RESCUE}

The phage-bacterium population densities have a major impact on the successful resolution of bacterial infection by the administered phage (Kasman et al., 2002; Abedon et al., 2011). Although, high phage densities are needed in order to arrest the growth of phage susceptible bacteria, sustained phage amplification is equally essential to further contain the bacterial multiplication and spread. But, phage amplification is further dependent on the concentration of the bacteria and therefore, a minimum threshold density of bacteria at target site is essential for this (Payne and Jansen, 2003; Tsonos et al., 2014). However, if low starting concentrations of bacteria are 
present or if phage is given at very early stages of infection, it make take some time for the bacteria to grow before reaching the threshold levels to support efficient phage amplification (Cairns et al., 2009; Malik et al., 2017). In such situations, phages may face early decay and drop in initial titer. Also, phages are equally susceptible to be cleared easily by the host immune factors, enzymes, and other tissue fluids or stress factors leading to low viable titter resulting in poor phage therapy outcomes (Dąbrowska, 2019; Principi et al., 2019).

In such situations, encapsulation offers an effective strategy showing potential of serving multiple purposes. The advantages range from protection and shielding of phage from outer environment, acting as an active delivery platform, sustained release of viable phages over a prolonged period etc. (ChoińskaPulit et al., 2015; Abdelsattar et al., 2019; Loh et al., 2020) Thus, encapsulation helps to maintain the phage titers to therapeutically effective levels over a significant time period so that once the bacterial threshold is attained, phage titers can further amplify leading to faster and effective resolution (Malik et al., 2017). Moreover, with modern nanoscale based encapsulation techniques, there has been a significant advancement in addressing many of the issues related to phage therapy. This section discusses the major advancements in encapsulating techniques towards phage therapeutics while supporting each new strategy with proof of data from in vitro and in-vivo studies reported lately.

\section{Encapsulation in Lipid Based Nanovesicles}

Lipid based nanovesicles represent an attractive and versatile drug delivery approach consisting of vesicle made from natural or synthetic lipids. These nanocarriers self-assemble and self-enclose to form spheres of lipid bilayers with an inner aqueous core ideal for encapsulating and protecting the sensitive drug inside (Puri et al., 2009; Bozzuto and Molinari 2015). Liposomes are one such category which has shown high biocompatibility with phages without affecting their efficiency and numbers during and post the encapsulation process (Singla et al., 2015; Chadha et al., 2017). Liposomes has a number of advantages that favour its use and further exploitation in phage delivery to target site with focus against gut pathogens, intracellular pathogens or biofilm associated pathogens etc. Liposomes aids in shielding phages from the action of the outer stress factors such as low $\mathrm{pH}$ of the gastric system during intestinal transit, clearance from reticuloendothelial system (RES), action of neutralising antibodies thus enhancing the in vivo circulation time (Takeuchi et al., 2005; Singla et al., 2015; Colom et al., 2015; Singla et al., 2016; Chhibber et al., 2018; Leung et al., 2018). Moreover, studies have shown that liposome encapsulation allowed phage to gain access even to the intracellular pathogens which is a serious drawback with free phages (Nieth et al., 2015). Besides being non-toxic and nonimmunogenic, liposome are easy to synthesize and the encapsulation techniques provide full control over the physical parameters such as vesicle size, encapsulating efficiency, and encapsulation dose etc. (Malam et al., 2009; Mallick and Choi, 2014; Lamichhane et al., 2018). Liposomes mimic biological membranes in terms of their structure, behaviour and fluidity and this allow them to undergo various conformational and dynamic transitions which are essential for many biological functions. For example, they can penetrate various host tissue barrier layers such as epidermal layers, intestinal mucosa, and deep seated tissue, even the bacterial mature biofilm areas allowing deeper delivery of the entrapped drug to such sites (Meers et al., 2008; Pierre and Dos, 2011; Hua, 2015; Rukavina and Vanic, 2016).

Liposome formation mostly follows classical techniques including electroformation, thin film hydration, sonication, solvent dispersion, evaporation, hydration or swelling etc., (Wagner and Vorauer-Uhl, 2011; Sawant and Torchilin, 2012). An advancement allowing finer tuning and better control of liposome production is the microfluidics method (van Swaay and deMello, 2013; Carugo et al., 2016). "Microfluidic" refers to the systems that process small quantities of fluids having dimensions at the microscale level in a geometrically constrained volume. This process allows production protocol to be miniaturised on chips and small devices thus giving higher throughput and analytical performance with reduced sample and reagent volumes (Duncombe et al., 2015; Wang et al., 2018; Murphy et al., 2017). Since less reaction volumes are used, the associated cost significantly decreases. Leung et al. (2018) investigated the use of microfluidic flow focusing to encapsulate Pseudomonas phages, PEV2 and PEV40. For this, a mixture of soy phosphatidylcholine and cholesterol (4:1) in absolute ethanol was injected into inner channel of a cross mixer followed by injection of the phage suspension from side channels. The resultant liposome sizes so formed varied as per the phage types. The size of liposomes encapsulating PEV2 was in the range of 135-218 nm while liposomes for Myovirus PEV40 was bigger i.e., 261-448 nm. The encapsulation efficiency of PEV2 was 59\% and that for PEV40 was $50 \%$ obtained at a total flow rate of $160 \mu \mathrm{l} / \mathrm{ml}$ and organic/aqueous flow rate ratio (FRR) of 2:3. Therefore, with this technique the encapsulation efficiency was enhanced (higher than that obtained with thin film hydration or extrusion method) while increasing the organic/aqueous flow rate ratio (FRR) with minimal titer reduction for both the phages. FRR has been identified as variable in the microfluidic process, with the highest impact on liposome size, poly-dispersity index (PI) and transfection efficiency (Kastner et al., 2014) and this can be controlled easily using the microfluidics approach. Similarly, Cinquerrui et al. (2018) also investigated the use of a novel co-flow microfluidic glass capillary device for the encapsulation of two model bacteriophages (E. coli T3 podovirus and Staphylococcus phage $\mathrm{K}$ ) in sub-micron sized liposomes. The authors were able to develop reproducible yield of sub-micron sized liposomes but the maximum attainable yield of encapsulated of T3 phage was affected by aggregation. Also, most of $S$. aureus phage.

$\mathrm{K}$ was found bound to the outside of the formed liposome instead of being trapped inside them. Henceforth, more work is required for further exploitation of this approach. Still, microfluidics represents a robust and high-throughput method for easy scalability and high reproducibility for development of size-controlled liposomes. 
Another advancement in liposomal based delivery systems include the surface modification of liposomes i.e., conjugation of suitable polymers on liposomal surface (dextran, chitosan, alginate or synthetic polymer such as polyethylene glycol (PEG), poly (vinyl alcohol) (PVA) etc. This enables to confer properties such as increased circulation time escaping RES inactivation or neutralisation from antibodies etc. (Akbarzadeh et al., 2013; Salmaso and Caliceti, 2013). PEGylation of liposomes has been used by past studies in an attempt to produce nanocarriers called stealth liposomes that are able to evade immune attack by macrophages while reducing the uptake process by the RES (Immordino et al., 2006; Allen and Cullis, 2013; Najlah et al., 2019). The polymer conjugation helps to sterically inhibit the various hydrophobic and electrostatic interactions with plasma proteins or cells. This helps in reducing the liposomal uptake further improving the bloodcirculation times essential for treating systemic infections (Harris et al., 2001; Immordino et al., 2006; Lombardo et al., 2016). Moreover, PEG on the surface results in a hydrophilic surface chemistry that allows unobstructed diffusion of such liposomes more easily through the epithelium (Malik et al., 2017). A recent one of its kind study by Otero et al. (2019) studied the bio-distribution of orally administered using flourochrome labelled phages encapsulated within liposomes using non-invasive in vivo imaging methodology to monitor their accumulation in stomach and intestinal tract employing athymic nude mouse model. Liposomes so prepared were less than $500 \mathrm{~nm}$ in size. To further extend the stability during intestinal transit and circulation, cholesterol and cholesteryl polyethylene glycol 600 Sebacate (Chol-PEG600) were incorporated during the synthesis process. Results showed that liposomes encapsulation of phage resulted in a significant increase of the labelled phages in the mouse stomach, detected even $6 \mathrm{~h}$ after oral administration with no significant decrease observed. However, non-encapsulated and encapsulated phages were similar when visualised in intestine. This prolonged persistence of liposomal phages in the stomach advocates their use for targeting enteric infections.

Many intracellular pathogens (M. tuberculosis, S. enterica) are able to survive and multiply well within the body's mononuclear phagocyte system (MPS) system. Bacteriophage encased liposomes is an appealing approach to treat as liposomes can accumulate in MPS due to their interaction with serum proteins (Bitounis et al., 2012; Bozzuto and Molinari, 2015) It has been shown that uptake by MPS for liposomes is enhanced when phosphatidylserine incorporating PEG is used (Malik et al., 2017). Further, Agrawal and Gupta (2000) reported the use of tuftsin, a tetra-peptide, which when conjugated with liposome can enhance the uptake of liposome by MPS and drug loaded tuftsin liposomes. This approach may prove highly effective against intracellular pathogens (Mycobacterium tuberculosis). Although phage loaded tuftsin-bearing liposomes has not been tested but this is a promising approach to enable lytic phage or phage cocktail reach the intracellular bacteria and contain the infections process.

Transfersomes are another lipid based nanocarriers that are much more flexible and adaptable. This high flexibility allows them to squeeze even through pores much smaller than their own diameter (Walve et al., 2011; Darwhekar et al., 2012). Due to their low toxicity, higher flexibility, transfersomes represent a better option for transdermal delivery than liposomes for treating deep skin infections (Sachan et al., 2013). Chhibber et al. (2017) reported that transfersome-entrapped phage cocktail showed better persistence and stability than free phages. Also, rats treated with the transfersome-entrapped phage cocktail resolved the experimental MRSA thigh infections within a period of 7 days, unlike the 20 -day period required for untreated animals.

Besides whole phages, phage lysins are also a potential approach in the antibacterial campaign representing a step ahead. Endolysins, a class of phage borne proteins are the natural hydrolytic enzymes responsible for the final lysis allowing release of progeny phages from the host bacteria. This they do so by acting on the bacterial cell wall and hydrolysing the peptidoglycan layer (Schmelcher et al., 2012; Love et al., 2020). These cell wall breaching enzymes show direct, instant killing, lacking the issues of associated resistance. Endolysins, being proteins and showing labile enzymatic activity suffer for similar or even more additional barriers than parent phages which include issue of stability, retention of their lytic spectrum at the infection site, in-vivo half-life etc. (Gondil and Chhibber, 2021). However, unlike phage encapsulation, endolysin delivery systems based research especially involving use of nanotechnology is still in the early stages. In one recent study, Silva et al. (2021) reported the successful encapsulation of MSlys endolysin in deformable liposomes against S. pneumoniae, with appreciable encapsulation efficiencies of $\sim 35 \%$, high stability and preservation of lytic potency seen during storage at $4^{\circ} \mathrm{C}$ over a test period of 1 year. Cytotoxicity studies also supported the biocompatible nature of MSlys-loaded liposomes while the endolysin loaded liposomes showed significant antipneumococcal activity against both planktonic and biofilm cells.

Similar past studies based on use of liposome and nano-based lipid carriers for encapsulating various phage endolysin showing improved stability and enhanced killing activity was observed unlike non-encapsulated endolysin (Gonzalez Menendez et al., 2018; Bai et al., 2019; Portilla et al., 2020). Table 2 details some of the major studies of both phages and phage encoded lysins benefitted from nano-encapsulation techniques. Figure 1 illustrates and summarizes the advantages offered by use of lipid based nanovesicles while overcoming the associated challenges.

\section{Nano-Emulsification}

Emulsification is one such technique of encapsulation in which uniform emulsions of water in oil can be formed by adding mixture of microbes, cells, enzymes, and drugs along with a compatible polymer and further dispersing this mixture to a another phase of vegetable oil (such as canola, corn oil etc.) (Tadros et al., 2004; Mcclements and Rao, 2011). The emulsions may further be stabilized by addition of emulsifiers and stabilizing agents. Nanoemulsions thus offer a new method of encapsulating sensitive molecules such as proteins, enzymes, phages in a nanoporous matrix. The confinement of bio-molecules within 
TABLE 2 | Recent studies focussed on use of Lipid Based Nanocarriers for improved delivery of therapeutic phage and phage endolysins.

Study objective

To evaluate the potential of liposome encapsulation of three phages of different morphologies in reducing gut load of Salmonella in poultry.
To evaluate the potential of liposomes encapsulated phages in treating Klebsiella pneumoniae induced burn wound infection.

To study the protective effect of encapsulation of S.aureus bacteriophage philPLA-RODI in three kinds of nanovesicles
Bacteriophage philPLA-RODI encapsulated in three kinds of nanovesicles (niosomes, liposomes, and transfersomes).
- Three phages (UAB_Phi20, UAB_Phi78, and UAB_Phi87) active against Salmonella Typhimurium were encapsulated in liposomes at a conc. of $10^{11} \mathrm{PFU} / \mathrm{ml}$ using the thin film hydration method and this was followed by their lyophilisation to study long term storage stability. Also the phage-liposomal preparation as tested for its titer reduction at simulated gastric fluid (SGF); pH 2.8.

- Next, the in vivo residence time of orally administered liposome phage cocktail (10 ${ }^{10}$ PFU/animal) was studied over $72 \mathrm{~h}$ and compared with free phage cocktail given to different group.

- Finally, the in -vivo efficacy of phage treatment was studied in the newly hatched broilers by first infecting them (orally on day 0) with $10^{7} \mathrm{CFU} /$ animal of $S$. Typhimurium 14,028 Rifr followed by oral administration of liposome phage cocktail (10 ${ }^{10}$ PFU/animal) and free phage cocktail to respective groups given daily for 8 days.

- Phage cocktail of five different phages (KØ1, $\mathrm{K} \varnothing 2, \mathrm{~K} \varnothing 3, \mathrm{~K} \varnothing 4$, and $\mathrm{K} \varnothing 5)$ in an equal proportion (1:1:1:1:1). were encapsulated in cationic liposomal formulation and subjected to complete characterisation.

- Experimental acute burn wound infection was established with K. pneumoniae $\left(10^{5} \mathrm{CFU} / \mathrm{ml}\right)$ followed by intraperitoneal administration of liposome loaded phage cocktail (LCP- $10^{5} \mathrm{PFU} /$ $\mathrm{ml}$ i.e MOl-1) to study its therapeutic potential in resolving wound infection in comparison to free phage cocktail (CP; non-encapsulated).
To develop and study the efficacy of endolysin encapsulated within cationic liposomes against Gram-negative enteric pathogens.
- Phage-derived endolysin BSP16Lys was isolated, characterized, and then encapsulated into a cationic liposome system.

- This was followed by testing its efficacy in bacterial reduction assays.
- Phage cocktail encapsulated in the liposomes (raning in size from 308-325 nm) showed appreciable encapsulation efficiency i.e., 49\% (UAB_Phi20), 47\% (UAB_Phi87), 48\% (UAB_Phi78). The titers postlyophilisation showed high counts in encapsulated phaegs than free phage cocktail i.e., $82 \%$ and $84 \%$ vs. 22 and $47 \%$ for encapsulated and non-encapsulated UAB-Phi20 and UAB-Phi87, respectively, but UAB_Phi78 showed sensitivity.

- In vivo residence time results showed prolonged retention of encapsulated phages than free phages in test animals after 48 and $72 \mathrm{~h}$. The percentage (\%) of chickens with phage shedding in cecum was $90.5 \%$ at $48 \mathrm{~h}$ vs. only $38 \%$ in free phage treated animals and 38.1 vs. $9.5 \%$ at $72 \mathrm{~h}$.

- The encapsulated phages showed prolonged sustained effect in reducing the Salmonella gut load even after ceasing the administration. Signficant decline in gut load was seen by day 8 (reduction of $3.8 \log$ CFU) and continued till day 15 (reduction by 1.5 log CFU) as compared to free phage group.

- Cationic phage loaded liposomes of $230 \mathrm{~nm}$ size and low poly-dispersity index (PI of 0.259 ) and high encapsulation efficiency of $79 \%$ were obtained.

- Control animals showed high bacterial load of $~ 8$ logs in skin while CP treated showed an initial 4 log count at $72 \mathrm{~h}$ further showing a decline. However, minimal counts not exceeding 2 logs was seen with LCP treated mice at $72 \mathrm{~h}$. Also, LCP treated mice showed peak phage titer up to 5 logs within $24 \mathrm{~h}$ in the affected skin site.

- Also, liposomal phage cocktail was able to protect all test animals even when therapy was delayed by $24 \mathrm{~h}$.

- All three types of preparations exhibited high phage encapsulation efficiency (62-98\%).

- Bacteriophage titers and infectivity was stable during 6 months of storage at $4^{\circ} \mathrm{C}$ with decreases in phage titer below 2 log units for all three types of nanovesicle. The stability of free phages was lower than that of encapsulated phages in all the formulations tested.

- Niosome loaded phages were stable even at low $\mathrm{pH} 4.5$ with only a reduction of $\sim 2$ log units from initial titer of $5.76 \mathrm{log} P F U / \mathrm{ml}$.

- Liposome encapsulated endolysin showed significant encapsulation efficiency i.e., $35.27 \%$.

- Also the encased enzyme showed reduction in Salmonella Typhimurium and E. coli cell counts by 2.2-log CFU/ml and 1.6-log CFU/ $\mathrm{ml}$, respectively, without requiring any membrane permeabilizing agent.

(Continued on following page) 
TABLE 2 | (Continued) Recent studies focussed on use of Lipid Based Nanocarriers for improved delivery of therapeutic phage and phage endolysins.

\begin{tabular}{|c|c|}
\hline Study objective & Study highlights \\
\hline $\begin{array}{l}\text { To evaluate the potential of encapsulating } S \text {. } \\
\text { aureus specific endolysin LysRODI in } \mathrm{pH} \\
\text { sensitive liposomes }\end{array}$ & $\begin{array}{l}\text { - Endolysin LysRODI was purified and } \\
\text { encapsulated (conc. } 100 \mu \mathrm{g} / \mathrm{ml} \text { ) in } \mathrm{pH} \text { sensitive } \\
\text { liposomes that release their content at } \mathrm{pH} \text { value } \\
\text { < } 5.5 \text {. } \\
\text { - This was followed by testing their encapsulation } \\
\text { efficacy and killing activity via turbidity assay, } \\
\text { time kill curves and anti-biofilm potential against } \\
\text { many S. aureus strains. }\end{array}$ \\
\hline
\end{tabular}

To evaluate therapeutic potential of liposome entrapped phage cocktail (MR-5 and MR-10) to resolve MRSA-induced diabetic excision wound infection.
To encapsulate mycobacteriophage in liposomes and to study the uptake by eukaryotic cells
- Wide spectrum MRSA phages (MR-5 and MR10) were used as cocktail mix [1:1] and further encapsulated in liposomal vesicles followed by characterisation studies.

- Wound excision model with $10^{8} \mathrm{CFU} / 50 \mu \mathrm{l}$ of locally injection of $S$. aureus 43,300 (MRSA strain) developed in diabetic mice.

- Cocktail loaded liposomal preparations (1:1) and free phage cocktail were then administered locally $\left(10^{10} \mathrm{PFU} / \mathrm{ml}\right)$ at the MRSA infected wound site in diabetic mice followed by studying wound healing parameters and wound bioburden.
- Two model phages i.e., mycobacteriophage TM4 or the reporter bacteriophage גeyfp were encapsulated in giant unilamellar liposomes gelassisted film hydration method and inverse emulsion.

- Further, the uptake of encapsulated phages was studied by immunofluorescence staining and confocal.
- Encapsulated lysin was fully active after its release form the nano-capsules and showed an encapsulation efficacy of $47 \%$.

- Antibacterial results showed that in time kill curves, reduction of 2 log units was seen post 60 min of incubation with S. aureus Sa9 cells (initial titer of $5.5 \log$ CFU). Also, in coincubation with exponential Sa9 cells at $\mathrm{pH}$ 5.0 , greatest level of killing was seen within 30 min (1.85 log units)

- The encapsulated endolysin exhibited significant killing activity (2 log units) against biofilm cells of different strains of $S$. aureus at $\mathrm{pH}$ 5.0.

- Uniform cationic liposomes with phage cocktail (MR-5 and MR-10) were formed of uniform size (230 nm) an low Pl-0.220 and high encapsulation efficiency close to $87 \%$.

- Liposomes showed high stability over 9 week period at $4^{\circ} \mathrm{C}$ with no aggregation seen (no change in $\mathrm{PI}$ values).

- In vivo efficacy results showed that in untreated mice, wound bio-burden went up to 8-9 log CFU/ml while in free cocktail group, although there was decline of 3 logs by day 3 but minimal load persisted even upto day 10. However, in liposomal phage cocktail treated mice, highly significant reduction of $4 \log$ CFU was seen by day 3 and negligible counts by day with visible reduction in wound size seen by day 7 .

- Complete resolution of induced wound infection and healing occurred within 9 days with liposome preparation unlike 20 days for control group.

- Encapsulated phages were taken up more efficiently by both cultured and phorbol 12myristate 13-acetate (PMA) differentiated THP-1 macrophages than free bacteriophages and able to co-localize with early- and recycling endosomes.

- This showed that such liposomes after their uptake by eukaryotic cells will be able to reach the target mycobacteria thus representing an ideal delivery system to take phages close to their intracellular bacteria.
References

Portilla et al. (2020)

Chhibber et al. (2018)

Nieth et al. (2015) 


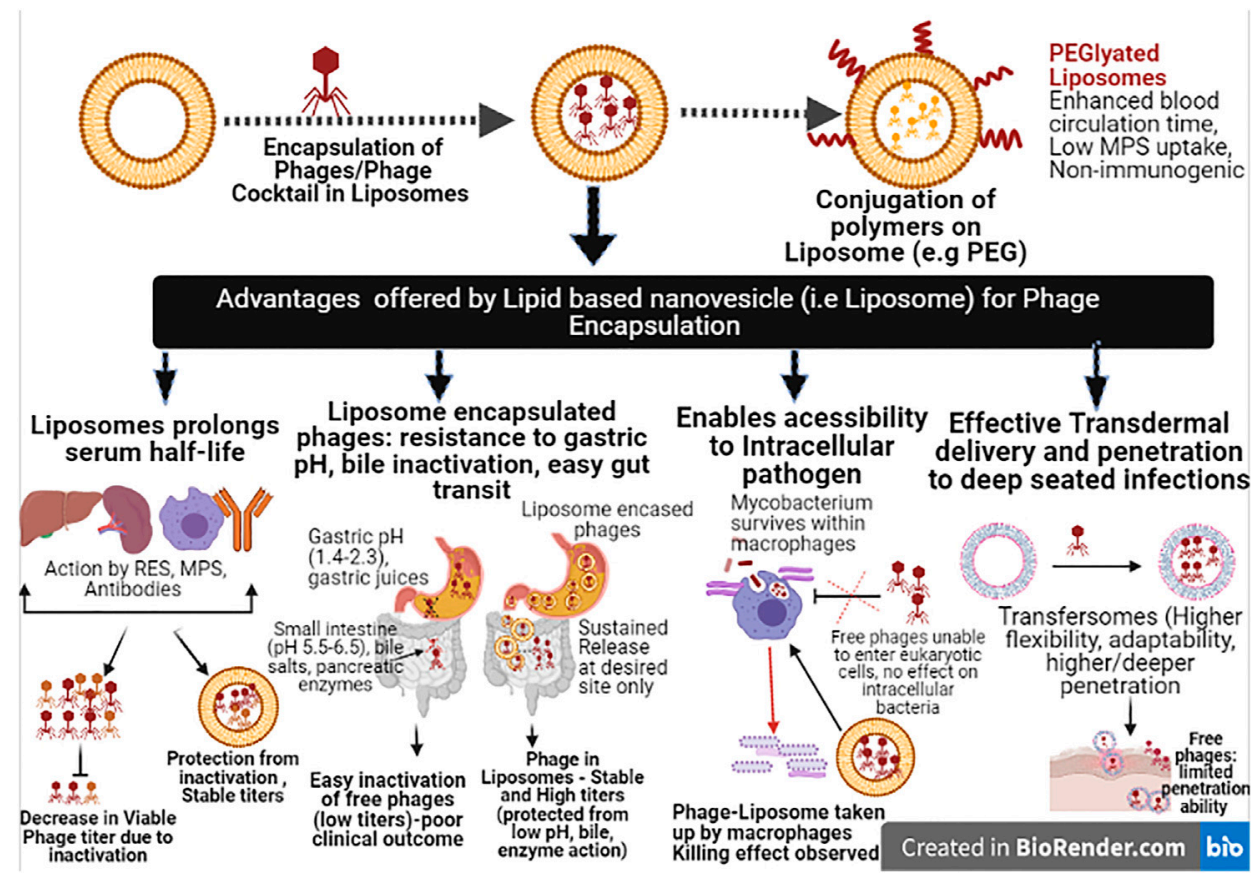

FIGURE 1 | Illustration detailing the advantages offered by Phage Encapsulation in Lipid based nanovesicles (RES, Reticuloendothelial system; MPS, Mononuclear phagocyte system; PEG, Polyethylene glycol).

and shape. A typical W1/O/W2 emulsion therefore consists of drops of inner water phase dispersed within oil phase which are further dispersed in outer water phase W2 (Kanouni et al., 2003; Dickinson, 2011). Next, is a version of this, in which one can control the number of inner drops encapsulated within the large drop (Chu et al., 2007; Deng et al., 2014; Azarmanesh et al., 2019). This variation can be highly useful for encapsulation of more than one type of phage i.e., in phage cocktails possible within a single large drop. Each phage type is present in different inner drop microenvironment thus allowing precise control over number and content of individual inner drops.

In addition, microfluidic approach also allows synthesis of multiple emulsion drops with concentric multiple shells around the core drop. Depending on the number of immiscible phases, it is possible to prepare different number of shells within the main drop. For example, we can have triple shells such as W1/O2/W3/ O4 or even quadruple shells (Abate et al., 2010; Malik et al., 2017; Vladisavljevic et al., 2017). Droplets with multiple onion like inner shells enable co-encapsulation of multiple active components (e.g., phage and antibiotic co-encapsulation or phage and antibacterial peptide or lysine co-encapsulation) and sequential release as per the desired choice. Such multiple shelled droplets enable to give maximum protection in case of highly sensitive phage or phage enzymes from outer stress environment. For example, the outer shell may protect phage from gastric $\mathrm{pH}$ as being acid resistant. Then, the next inner shell may be suitable for burst release for immediate action and release of high numbers of phages to immediately contain the bacterial population. The last or inner shells may be suited for sustained phage release for maintain a slow yet sustained release pattern especially essential for treating chronic infections and this may also avoid the need of repeated phage administration.

Next, we discuss few studies focussed on use of nanoemulsions based strategies for delivery of phages. Balcao et al. (2014) reported the nano-emulsification of a broad spectrum lytic phage i.e., phi-2/2, active against enteric Salmonella and Escherichia coli producing multiple emulsions called water-inoil-in-water (W/O/W) emulsions. For this, the team first dissolved the phage in inner aqueous phase, then dispersed in lipid oily phase (melted lipid mix consisting of glycerol, Softisan, and soybean phosphatidylcholine and finally an external aqueous phase (Lutrol F68) was then added to produce stable lipid nanoballoons called Win/O/Wext dispersions of phage particles. Results showed that such nanoemulsions allowed long term storage of phi-2/2 (tested over 92 days) with no loss of phage infectivity while encompassing full stabilization of phage three-dimensional structure suitable for use in aerosolised forms. Such multiple emulsions with compartmentalized internal structure represents a better strategy allowing to carry both polar and nonpolar molecules with higher control over release of the therapeutic molecule. On similar grounds, Rios et al. (2017) also developed aqueous core lipid nanodropletes using $\mathrm{W} / \mathrm{O} / \mathrm{W}$ multiple emulsion platform for encasing broad spectrum lytic $P$. aeruginosa specific phage. These stable nanoemulsions (called ME10 and ME1000) were further used to develop isotonic derivatives for administering the phage via nebulisation route to treat pulmonary pneumonia allowing the targeted release of phages directly at required site. Results showed 90\% phage encapsulation efficiency of ME1000. The isotonic derivatives so formed when tested showed no cytotoxic/genotoxic effect 
on A549 and V79 cell lines thus proving safe for in vivo use. Studies have also demonstrated enhanced antibacterial activity seen following encapsulation of phage $\mathrm{K}$ in oil-in-water nanoemulsions when compared to non-encapsulated preparations (Esteban et al., 2014). In this study, nano-emulsions were produced by a unique thermal phase inversion process using $5 \%(\mathrm{w} / \mathrm{w})$ soybean oil as the organic phase and BrijO10 and SM buffer as aqueous phase incorporating phage $\mathrm{K}$. These stable nanoemulsions showed enhanced antibacterial activity as shown by complete lysis of three S. aureus strains (strains H560, H325, and Btn766) within the first 4 hours with concentration dropping to zero. Bacterial regrowth for S. aureus $\mathrm{H} 560$ started at $8 \mathrm{~h}$ and for $\mathrm{H} 325$ and Btn766 at about $12 \mathrm{~h}$ with phage in plain SM buffer while this did not occur with bacteriophage nanoemulsion formulations. All these strains showed significantly reduced growth in terms of $\mathrm{O}$. D as well. When strains were grown in presence of 1:1 diluted emulsion there was a decrease of $13 \% \mathrm{O}$. D for strain $\mathrm{H} 560,21 \%$ reduction in strain $\mathrm{H} 325$, 55\% reduction seen in strain Btn766 as compared to O. D in tryptone soy broth (TSB). Also, these nanoemulsions were more stable showing no significant drop in lytic efficiency when stored for 10 days either at room temperature or at $4^{\circ}$ C.Moreover, such oil-in-water nanoemulsions exhibit enhanced transdermal penetration into deeper layers with higher biocompatibility with the skin tissue due to lesser amount of surfactant required for their preparation (Bouchemal et al., 2004; Azeem et al., 2009). This advocates use of nano-emulsified phage preparations for use in superficial and deep seated skin infections and wound applications/dressings allowing sustained release of active phages.

\section{Nanofibers: A New Delivery Platform}

Nanofibers represent another important outcome of nanotechnology in which nano-sized continuous fibers are produced with controlled surface morphology by a process called "Electro-spinning". Briefly, the process of electrospinning involves a polymer solution filled in a syringe which is then forced through the syringe needle in form of a drop. To this drop, very high voltage is applied that leads to deformation from round to conical forms (i.e., Taylor cone effect) and finally as the voltage exceeds a threshold value, there occurs formation of one or more jets that travel to a metal collector where the solvent evaporates and formation of nano-sized fibers initiates at the surface of the collector (Teo and Ramakrishna, 2006; Bhattarai et al., 2018; Shahriar et al., 2019). These nanofibers enjoy the properties of a high surface area to volume ratio, enhanced flexibility, ease of surface functionalities and good mechanical performace and resistance (Gugulothu et al., 2019; Dos Santos et al., 2020). The best thing is that a large number of bioactive molecules and even live cells (e.g., antibacterial, anti-inflammatory, anti-cancer drugs, nucleic acids, DNA, enzymes, vitamins, proteins, probiotics, viruses, and algae etc.) can be mixed with the polymer solution during the electrospinning process leading to formation of electrospun nanofibers while incorporating the drug molecule with high efficiency and thus acting as a suitable delivery system (Potrc et al., 2015; Torres-Martínez et al., 2018; Monfared et al., 2020). Also, one can optimise the process of nanofiber formation by controlling the parameters during synthesis time so as to change fiber size, thickness, shape, porosity, conductivity, degradation rates, times, and response etc. as per the ideal requirements (Xue et al., 2019). A range of polymers [poly (lactic-co-glycolic acid) (PLGA), chitosan, polyvinyl alcohol, poly ( $\varepsilon$-caprolactone), Poly ethylene oxide (PEO), cellulose, alginate, collagen, and elastin etc.) have been used for producing nanofibers giving a wide option for selection and moreover, biodegradable polymers used are highly bio-compatible and less immunogenic (Bonino et al., 2011; Mengistu Lemma et al., 2016; Yew et al., 2018; Gugulothu et al., 2019).

Eletrospinning process can be manipulated in several ways to produce varying types of nanofibers (Alghoraibi and Alomari, 2018; Xue et al., 2019). Firstly, we have simple or basic electrospinning done with a single polymer allowing drug to be embedded evenly within the nanofibers. If drug loaded nanocarriers are mixed with the polymer, one will obtain nanocarriers attached to the outside of the fibers. Next, is the blend of two or more polymers,

which we refer as blend electrospinning that ideally helps in improved dispersion. Then, we have coaxial electrospinning process in which core-shell fibers are formed with drug within the core and polymer woven in the outer shell. Such coaxially electrospun nanofibers allow biphasic release pattern with an initial burst release from the core-sheath followed by extended periods of sustained release while many sensitive biomolecules are far better shielded within the core-shells than basic electrospinning (Lu et al., 2016; Xue et al., 2019). These core-shell nanofibers can either be multi-matrix or can be reservoir type depending on whether the drug is loaded in both layers or just within the core layer only. Besides this, there is emulsion electrospinning in which the drug forms emulsions either water-in-oil or oil-in-water types with formation of core-shell structured nanofibers. The degradable polymer is first solubilized in a proper organic solvent forming a continuous phase and the active drug is dissolved in the aqueous solution leading to formation of the water phase (Haider et al., 2018; Kumar et al., 2019). Such nanofibers offer superior protection of the incorporated drug from inactivation due to external stress conditions. Finally, there is gas jet type of modification, in which the process combines electrospinning with a gas jet device that allows for formation of highly uniform and ultra-fine nanofibers (Kenry and Lim, 2017). With all these newer modifications (as depicted in Figure 2), electrospun nanofibers can be produced to fit into any of the classes such as immediate drug release nanofibers, biphasic drug release (initial high burst and later sustained release) nanofibers, prolonged drug release nanofibers and stimulusactivated drug-release nanofibers (i.e., release in response to external stimuli when they meet a particular $\mathrm{pH}$ or temperature etc.)

\section{Nanofibers and Therapeutic Phage Delivery}

Nanofibers so produced can be conjugated with range of active functional agents and lytic phages represent one of them. The biodegradable polymers are the best choice matrices for the deposition of phage within these fibers. Studies on the use of electrospun nanofibers for delivery of phages are presently scarce but the results are encouraging. Salalha et al. (2006) showed the 


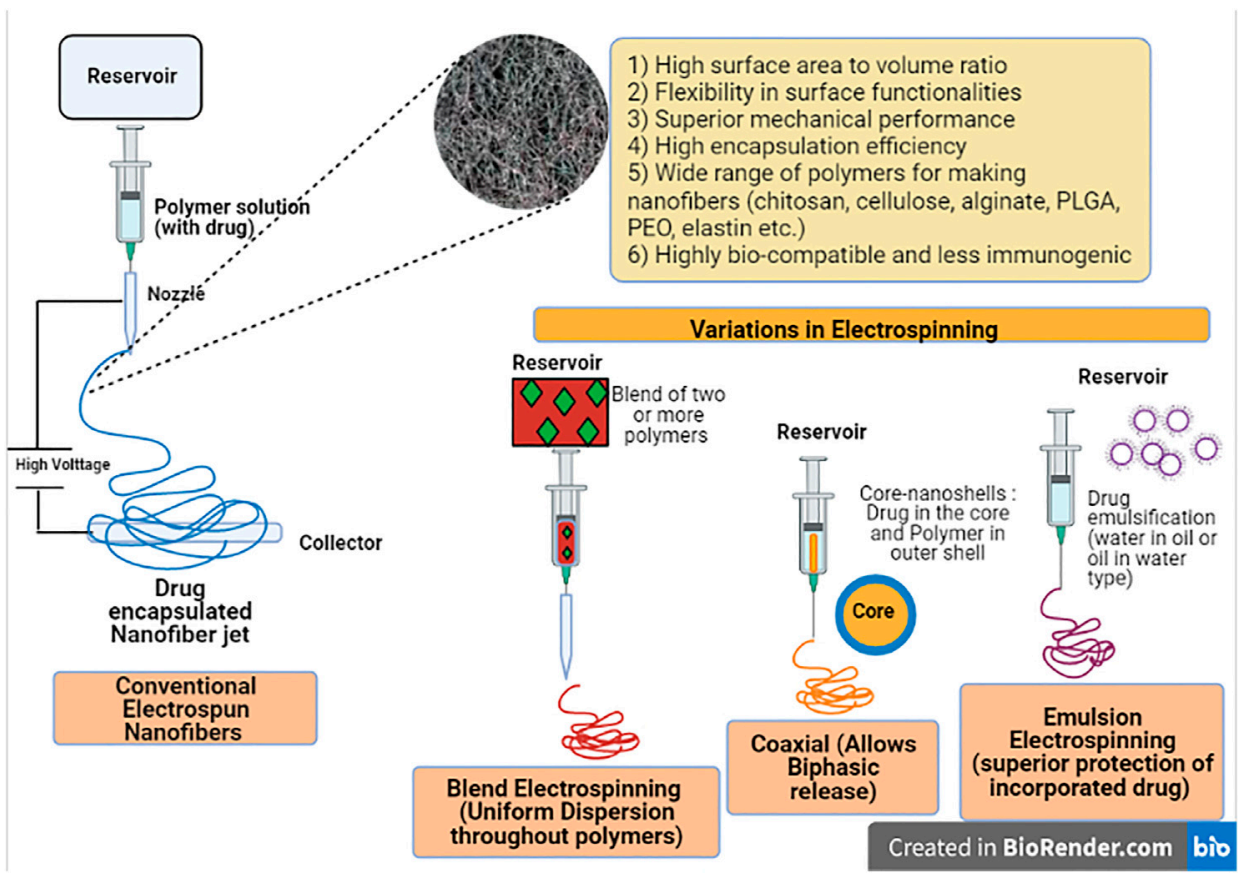

FIGURE 2 | Diagrammatic illustration of Electrospun Nanofibers and its modifications as the new drug delivery platform.

successful basic electrospun nanofibers for encapsulation of T4, T7, and lambda phage in poly-vinyl alcohol (PVA) polymer resulting in maintenance of good viability for at least 3 months at $4^{\circ} \mathrm{C}$. Although in vivo efficacy of these nanofibers was not studied, but this study offered the first hope of electrospinning as an ideal solution against phage viability losses. Similarly, nanofibers embedded with phage provided protection which was further improved with addition of storage media (SM) buffer and sucrose over an extended period of 8 weeks at $20^{\circ} \mathrm{C}$ (Koo et al., 2016). However, one drawback associated was loss of lytic activity of phages once released from such nanofibers and the possible reason for this is the rapid dehydration of bacteriophage during the spinning process (Lee and Belcher, 2004). Although addition of trehalose, sucrose, and mannitol exhibit a protective effect from high voltage and spinning process but loss of activity was still observed (Dai et al., 2014).

Korehei and Kadla (2013) addressed this issue by using two different electrospinning processes: emulsion and coaxial electrospinning. In emulsion electrospinning, pre-encapsulation of bacteriophage T4 in alginate matrix was first done followed by electrospinning whereas in coaxial electro spinning process, the phage was allocated to the core of the fibers. Emulsion electrospun fibers with $\mathrm{T} 4$ bacteriophages incorporated in alginate capsules, provided a shielding barrier against rapid dehydration stress with only a slight drop in phage activity observed. Further, the most promising results were obtained when coaxial nanofibers with $\mathrm{T} 4$ bacteriophages were formed as full bioactivity was maintained. Coaxial spinning produces continuous core/shell morphology with a more uniform distribution of phage in the core of the fibre and no drastic change in the osmotic environment leading to retention of full lytic activity.
Another important application of nanofibers is their use in wound dressing allowing sustained release of phages at wound site while maintain complete infectivity. This was reported by Nogueira et al. (2017) in which the team developed a novel method of covalent immobilization via amide linkages of vB_Pae_Kakheti25 bacteriophage capsid on poly-caprolactone (PCL) nanofibers with oriented phage tails ready to interact with the bacteria.

These immobilised phage nanofibers showed as high as six $\log$ reduction $(99.9 \%)$ in $P$. aeruginosa counts while utilising PCL polymer's properties of skin regeneration, high elasticity and resistance to breakdown from skin enzyme etc. Such systems represent as an ideal approach for sustained release of phage from the wound dressing while promoting wound healing and skin regeneration, a favourable two in one approach for treating chronic skin ailments (Sarhan and Azzazy, 2017).

One important application is the use of stimulus activated smart release nanofibers for release of phages as and when required. This is especially suitable in oral delivery of phages. These smart release nanofibers would not allow the release of phages at low $\mathrm{pH}$ of stomach thus shielding them during gastric transit. Once the phage loaded nanofibers reach the intended site (e.g., colon) and meet the desired $\mathrm{pH}$, phage release will be initiated in desired format (burst or sustained). Delivery of antibiotic and anticancer drugs, probiotics using cellulose smart has been reported (Demirci et al., 2014; Hujaya et al., 2018; Singh et al., 2018). Such results advocate more studies on use of $\mathrm{pH}$ responsive phage embedded nanofibers to address the issue of viability and titer loss during gut transit. 


\section{Stimuli-Responsive Nanocarriers}

Another technique for drug delivery is the smart release platforms which allow the release of active drugs at the desired site in response to an external stimuli. This stimuli can be a particular $\mathrm{pH}$, temperature, or a molecule released by bacteria, an enzyme, protein, cytokine, and signalling molecule etc. The stimuli triggered release concept has been the subject of interest as it allows control over the dosing releasing the drug where, and when it is desired achieving high local concentrations (Webber, 2016; Wells et al., 2019; Abdo et al., 2020). Let's discuss the commonly used smart release DDS available and its outcome on phage delivery.

One such synthetic polymer widely used is Eudragit ${ }^{\circledR}$. This belongs to family of $\mathrm{pH}$ responsive polymethacrylate polymers that respond to changes in $\mathrm{pH}$ and come in different grades (Nikam et al., 2011; Thakral et al., 2013). For example, Eudragit ${ }^{\circledR}$ L100 dissolves at $\mathrm{pH}$ six while Eudragit ${ }^{\circledast}$ S100 at pH 7. Hence, use of such polymers as encapsulating matrix will enable the drug to be released only at the right time and at the right site when the desired $\mathrm{pH}$ is met. Eudragit $\mathrm{L}$ and $\mathrm{S}$ are two forms that form films/ coatings resistant to low gastric $\mathrm{pH}$ thereby allowing the drug to easily bypass the stomach and reach the intestine. These films are soluble in intestinal fluid at $\mathrm{pH}$ six and seven whereby they release the active drug (Vibhooti et al., 2013; Mehta et al., 2013). This same scheme can be employed for encapsulating

phages and protecting them from gastric $\mathrm{pH}$ allowing release only at near neutral $\mathrm{pH}$ at the desired intestinal target site essential for success of oral phage therapy targeting various enteric infections. Similarly, Eudragit RS100 and E100 have been used for triggered release at acidic $\mathrm{pH}$ such as during vaginal delivery (Leyva-Gomez et al., 2018). There are recent studies that have explored the potential of this $\mathrm{pH}$ responsive polymer for triggered phage release at desired $\mathrm{pH}$. Although these studies have reported the formation of Eudragit microspheres and microparticles, the encouraging results of these studies on enhancing phage stability advocate scaling down the process for formation of nanospheres and nano-coatings. Few studies are worth mentioning. Vinner at al. (2017) reported the encapsulation of $C$. difficile specific phage CDKM9 in EudragitS100 with and without alginate. By adopting a unique microfluidic system using flow focussing glass microcapillary device, the phage preparations were encased within the uniform core-shell microspheres so formed. Results showed that the phage titers did not drop when such phage loaded microparticles were exposed to simulated gastric fluid environment of $\mathrm{pH}$ two for $3 \mathrm{~h}$ and phage release was triggered with high titers of viable phage moving out at the desired $\mathrm{pH}$ 7. Same group further developed a unique scalable low shear membrane emulsification process through which they produced uniform $\mathrm{pH}$-responsive microparticles containing E. coli phages encapsulated in EudragitS100 and alginate (Vinner et al., 2019). The encapsulated phages were completely stable and well-protected from gastric $\mathrm{pH}$ stress, easy inactivation from bile fluids, enzymatic action etc. Such microcapsules are very apt and suitable for delivering high numbers of viable phage at the target site in the intestinal system. Moreover, development of scalable processes such as the membrane emulsification process is highly required as it represents a potential platform for producing large scale quantities (following GMP norms) of such phage loaded microspheres for oral solid dosage forms and widespread clinical testing.

Another polymer that shows triggered response to temperature as the stimuli, is Poly ( $\mathrm{N}$-isopropylacrylamide) (PNIPAM). It is a thermally responsive polymer that undergoes a reversible phase transition in response to changes in external temperature. There occurs a sharp phase transition when the polymer is exposed to water at $32^{\circ} \mathrm{C}$ called lower critical solution temperature (LCST) phase transition whereby gel changes from swollen hydrated state to a shrunken or collapsed state, losing about $90 \%$ of its volume (Heskins and Guillet, 1968; Lima et al., 2016; Pal et al., 2019). There has been limited study on use of this polymer for developing drug delivery platform for phages and hence this needs further exploitation.

Hathaway et al. (2015) utilised PNIPAM nanosphere copolymerized with allylamine (ALA) for development of smart delivery system of phages at wound site allowing phage loaded nanospheres to collapse (allowing phage release in high numbers) at an elevated temperature during an active bacterial infection site. The formulated PNIPAM-co-ALA nanoparticles were anchored to non-woven polypropylene to simulate a wound dressing and then soaked with phage $\mathrm{K}$ solution $\left(10^{9} \mathrm{PFU} / \mathrm{ml}\right)$ for $4 \mathrm{~h}$ at $25^{\circ} \mathrm{C}$. This phage loaded thermal responsive PNIPAMco-ALA nanospheres collapsed at $37^{\circ} \mathrm{C}$ releasing the phage $\mathrm{K}$ leading to lysis of clinical S. aureus isolate ST228. However, at $25^{\circ} \mathrm{C}$, the system remained intact with no release of phages with no decline seen in the bacterial counts. In another study by the same group, Hathaway et al. (2016) reported the successful encapsulation of two agents i.e., phage endolysin CHAPK and the bacteriocin lysostaphin in PNIPAM nanoparticles and then tested their potency against control of MRSA mediated wound infections. PNIPAM nanoparticles showed effective release of the enzybiotic cocktail in a temperature controlled manner. CHAPK/ lysostaphin released from PNIPAM showed significant bacterial lysis with four $\log$ reduction at $37^{\circ} \mathrm{C}$ while growth was maintained at temperature of $32^{\circ} \mathrm{C}$ in case of uninfected skin temperature. In addition to targeting wound infections, such nano-coatings may prove highly useful in case of implants and catheters whereby any initial infection of foreign implants will cause a thermal change and this will trigger phage release at the implant site. Moreover, phage and antibiotic can be encapsulated together in the nanospheres and further coated onto implants for exploring the dual potential of the two agents as reported by Kaur et al. (2016) against orthopaedic implant infections.

\section{CONCLUSION}

Modern phage therapy has come a long way and there has been some major case studies reporting successful use of phage therapy (on compassionate basis) in treating chronic and refractory infections. Although direct indication of success of these human studies using nano-based advances has not been tested or reported, but looking at the success stories in individual 
patients, the advocated use of improved nano-based delivery systems in future will definitely further enhance the treatment success rates. There has been recent reports of case studies whereby phage cocktail therapy has shown improvement of chronic respiratory infections from drug resistant strains $(P$. aeruginosa, Acinetobacter baumannii, Burkholderia complex, Achromobacter xylosoxidans etc.) seen in CF patients (Duplessis et al., 2019; Aslam et al., 2020; Lebeaux et al., 2021). In such cases, the use of inhalable liposomal phage formulations for nebulised administration may be a step ahead for further maintaining phage titers and protection from local immune attack thus enhancing the treatment outcome in such difficult to treat pulmonary infections (Bassetti et al., 2020). Also, use of multiple nano-emulsions and core shell nanofibers may offer a better compartmentalization and sustained release of phage cocktails. Similarly, successful case reports of treatment of diabetic toe wound infections by local application of $S$. aureus phage cocktail (Fish et al., 2016) and foreign body infections such as prosthetic implant infection whereby phage cocktails were locally injected into the joint cavity have been reported (Ferry et al., 2018; Nir-Paz et al., 2019). Here, the stimuli-responsive nano-carriers and electrospun nanofibers may be an ideal strategy to enhance the bioavailability of delivered phages in the affected wound site and implant area in a sustained manner for longer duration. Also, such smart release systems will enable the timely

\section{REFERENCES}

Abate, A. R., Hung, T., Mary, P., Agresti, J. J., and Weitz, D. A. (2010). Highthroughput Injection with Microfluidics Using Picoinjectors. Proc. Natl. Acad. Sci. U S A. 107 (45), 19163-19166. doi:10.1073/pnas.1006888107

Abdelsattar, A. S., Abdelrahman, F., Dawoud, A., Connerton, I. F., and El-Shibiny, A. (2019). Encapsulation of E. coli Phage ZCEC5 in Chitosan-Alginate Beads as a Delivery System in Phage Therapy. AMB Express 9 (1), 87. doi:10.1186/ s13568-019-0810-9

Abdo, G. G., Zagho, M. M., and Khalil, A. (2020). Recent Advances in StimuliResponsive Drug Release and Targeting Concepts Using Mesoporous Silica Nanoparticles. Emergent Mater. 3, 407-425. doi:10.1007/s42247-020-00109-x

Abedon, S. T., Herschler, T. D., and Stopar, D. (2001). Bacteriophage Latent-Period Evolution as a Response to Resource Availability. Appl. Environ. Microbiol. 67 (9), 4233-4241. doi:10.1128/aem.67.9.4233-4241.2001

Abedon, S. T., Kuhl, S. J., Blasdel, B. G., and Kutter, E. M. (2011). Phage Treatment of Human Infections. Bacteriophage 1 (2), 66-85. doi:10.4161/bact.1.2.15845

Abedon, S. T. (2009). Kinetics of Phage-Mediated Biocontrol of Bacteria. Foodborne Pathog. Dis. 6 (7), 807-815. doi:10.1089/fpd.2008.0242

Abedon, S. T. (2014). Phage Therapy: Eco-Physiological Pharmacology. Scientifica (Cairo) 2014, 581639. doi:10.1155/2014/581639

Abedon, S. T., and Thomas-Abedon, C. (2010). Phage Therapy Pharmacology. Curr. Pharm. Biotechnol. 11 (1), 28-47. doi:10.2174/138920110790725410

Agrawal, A. K., and Gupta, C. M. (2000). Tuftsin-bearing Liposomes in Treatment of Macrophage-Based Infections. Adv. Drug Deliv. Rev. 41 (2), 135-146. doi:10.1016/s0169-409x(99)00061-7

Akbarzadeh, A., Rezaei-Sadabady, R., Davaran, S., Joo, S. W., Zarghami, N., Hanifehpour, Y., et al. (2013). Liposome: Classification, Preparation, and Applications. Nanoscale Res. Lett. 8 (1), 102. doi:10.1186/1556-276X8-102

Alghoraibi, I., and Alomari, S. (2018). "Different Methods for Nanofiber Design and Fabrication," in Handbook of Nanofibers. Editors A. Barhoum, M. Bechelany, and A. Makhlouf (Cham: Springer), 1-46. doi:10.1007/978-3319-42789-8_11-2 release of the drug as soon as bacterial multiplication initiates (causing change in stimuli such as temperature or $\mathrm{pH}$ ) thus able to arrest the infection or biofilm formation process at the initial stages itself.

In the present scenario, where bacterial resistance has become an alarming crisis responsible for the increased number of deaths due to infections not responding to antibiotic treatment, phage therapy definitely offers a ray of hope. It needs to be strongly promoted and worked on with focussed approach towards addressing the major limitations. The present review has detailed out the major pharmacological barriers and the new developments and solutions offered by nanotechnology. These advances in nanodelivery based strategies exhibit strong potential in enhancing/ improving the therapeutic and clinical outcome of the delivered phage while overcoming many of the major drawbacks that are still unmet. This advocates further research in this direction so that phage therapy can see wider clinical success and faster progress.

\section{AUTHOR CONTRIBUTIONS}

Conceptualization of idea: SK, VS. Acquisition of data: AK, AKN, VG, ST, MA. Analysis of extracted data: SK, AK, AKN, VG, ST, MA. Drafting of manuscript: SK, AK, AKN, VG, ST, MA, VS. Final Editing and Approval: VS.

Álvarez, A., Fernández, L., Iglesias, B., Rodríguez, J., Rodríguez, A., and García, P. (2019). Phage Therapy: Unexpected Drawbacks to Reach Hospitals. Future Virol. 14, 779-782. doi:10.2217/fvl-2019-0154

Antimicrobial resistance (2020). WHO Fact Sheet. Available at: https://www.who. int/news-room/fact-sheets/detail/antimicrobial-resistance (Accessed October 13, 2020).

Aslam, S., Lampley, E., Wooten, D., Karris, M., Benson, C., Strathdee, S., et al. (2020). Lessons Learned from the First 10 Consecutive Cases of Intravenous Bacteriophage Therapy to Treat Multidrug-Resistant Bacterial Infections at a Single center in the United States. Open Forum Infect. Dis. 7 (9), ofaa389. doi:10.1093/ofid/ofaa389

Azarmanesh, M., Bawazeer, S., Mohamad, A. A., and Sanati-Nezhad, A. (2019). Rapid and Highly Controlled Generation of Monodisperse Multiple Emulsions via a One-step Hybrid Microfluidic Device. Sci. Rep. 9, 12694. doi:10.1038/ s41598-019-49136-7

Azeem, A., Rizwan, M., Ahmad, F. J., Iqbal, Z., Khar, R. K., Aqil, M., et al. (2009). Nanoemulsion Components Screening and Selection: a Technical Note. AAPS PharmSciTech 10 (1), 69-76. doi:10.1208/s12249-008-9178-x

Baggot, J. D. (1990). Pharmacokinetic-pharmacodynamic Relationship. Ann. Rech Vet. 21(Suppl. 1), 29S-40S.

Bai, J., Yang, E., Chang, P. S., and Ryu, S. (2019). Preparation and Characterization of Endolysin-Containing Liposomes and Evaluation of Their Antimicrobial Activities against Gram-Negative Bacteria. Enzyme Microb. Technol. 128, 40-48. doi:10.1016/j.enzmictec.2019.05.006

Balcão, V. M., Glasser, C. A., Chaud, M. V., del Fiol, F. S., Tubino, M., and Vila, M. M. (2014). Biomimetic Aqueous-Core Lipid Nanoballoons Integrating a Multiple Emulsion Formulation: A Suitable Housing System for Viable Lytic Bacteriophages. Colloids Surf. B Biointerfaces 123, 478-485. doi:10.1016/ j.colsurfb.2014.09.045

Bassetti, M., Vena, A., Russo, A., and Peghin, M. (2020). Inhaled Liposomal Antimicrobial Delivery in Lung Infections. Drugs. 80 (13), 1309-1318. doi:10.1007/s40265-020-01359-z

Batinovic, S., Wassef, F., Knowler, S. A., Rice, D. T. F., Stanton, C. R., Rose, J., et al. (2019). Bacteriophages in Natural and Artificial Environments. Pathogens 8 (3), 100. doi:10.3390/pathogens 8030100 
Benet, L. Z. (1978). Effect of Route of Administration and Distribution on Drug Action. J. Pharmacokinet. Biopharm. 6 (6), 559-585. doi:10.1007/BF01062110

Bhattarai, R. S., Bachu, R. D., Boddu, S. H. S., and Bhaduri, S. (2018). Biomedical Applications of Electrospun Nanofibers: Drug and Nanoparticle Delivery. Pharmaceutics 11 (1), 5. doi:10.3390/pharmaceutics11010005

Bichet, M. C., Chin, W. H., Richards, W., Lin, Y. W., Avellaneda-Franco, L., Hernandez, C. A., et al. (2021). Bacteriophage Uptake by Mammalian Cell Layers Represents a Potential Sink that May Impact Phage Therapy. iScience 24, 102287. doi:10.1016/j.isci.2021.102287

Bitounis, D., Fanciullino, R., Iliadis, A., and Ciccolini, J. (2012). Optimizing Druggability through Liposomal Formulations: New Approaches to an Old Concept. ISRN Pharm. 2012, 738432. doi:10.5402/2012/738432

Bogovazova, G. G., Voroshilova, N. N., and Bondarenko, V. M. (1991). [The Efficacy of Klebsiella pneumoniae Bacteriophage in the Therapy of Experimental Klebsiella Infection]. Zh. Mikrobiol. Epidemiol. Immunobiol. 4, 5-8.

Bonino, C. A., Krebs, M. D., Saquing, C. D., Jeong, S. I., Shearer, K. L., Alsberg, E., et al. (2011). Electrospinning Alginate-Based Nanofibers: From Blends to Crosslinked Low Molecular Weight Alginate-Only Systems. Carbohydr. Polym. 85, 111-119. doi:10.1016/j.carbpol.2011.02.002

Bouchemal, K., Briançon, S., Perrier, E., and Fessi, H. (2004). Nano-emulsion Formulation Using Spontaneous Emulsification: Solvent, Oil and Surfactant Optimisation. Int. J. Pharm. 280 (1-2), 241-251. doi:10.1016/ j.ijpharm.2004.05.016

Bozzuto, G., and Molinari, A. (2015). Liposomes as Nanomedical Devices. Int. J. Nanomedicine 10, 975-999. doi:10.2147/IJN.S68861

Brives, C., and Pourraz, J. (2020). Phage Therapy as a Potential Solution in the Fight against AMR: Obstacles and Possible Futures. Palgrave Commun. 6, 100. doi:10.1057/s41599-020-0478-4

Cairns, B. J., Timms, A. R., Jansen, V. A., Connerton, I. F., and Payne, R. J. (2009). Quantitative Models of In Vitro Bacteriophage-Host Dynamics and Their Application to Phage Therapy. Plos Pathog. 5 (1), e1000253. doi:10.1371/ journal.ppat.1000253

Capparelli, R., Parlato, M., Borriello, G., Salvatore, P., and Iannelli, D. (2007). Experimental Phage Therapy against Staphylococcus aureus in Mice. Antimicrob. Agents Chemother. 51 (8), 2765-2773. doi:10.1128/ AAC.01513-06

Carmody, L. A., Gill, J. J., Summer, E. J., Sajjan, U. S., Gonzalez, C. F., Young, R. F., et al. (2010). Efficacy of Bacteriophage Therapy in a Model of Burkholderia Cenocepacia Pulmonary Infection. J. Infect. Dis. 201 (2), 264-271. doi:10.1086/ 649227

Carugo, D., Bottaro, E., Owen, J., Stride, E., and Nastruzzi, C. (2016). Liposome Production by Microfluidics: Potential and Limiting Factors. Sci. Rep. 6, 25876. doi:10.1038/srep25876

Chadha, P., Katare, O. P., and Chhibber, S. (2017). Liposome Loaded Phage Cocktail: Enhanced Therapeutic Potential in Resolving Klebsiella pneumoniae Mediated Burn Wound Infections. Burns 43 (7), 1532-1543. doi:10.1016/ j.burns.2017.03.029

Chhibber, S., Kaur, J., and Kaur, S. (2018). Liposome Entrapment of Bacteriophages Improves Wound Healing in a Diabetic Mouse MRSA Infection. Front. Microbiol. 9, 561. doi:10.3389/fmicb.2018.00561

Chhibber, S., Kaur, S., and Kumari, S. (2008). Therapeutic Potential of Bacteriophage in Treating Klebsiella pneumoniae B5055-Mediated Lobar Pneumonia in Mice. J. Med. Microbiol. 57, 1508-1513. doi:10.1099/ jmm.0.2008/002873-0

Chhibber, S., Kaur, T., and Sandeep Kaur, S. (2013). Co-therapy Using Lytic Bacteriophage and Linezolid: Effective Treatment in Eliminating Methicillin Resistant Staphylococcus aureus (MRSA) from Diabetic Foot Infections. PLoS One 8 (2), e56022. doi:10.1371/journal.pone.0056022

Chhibber, S., Shukla, A., and Kaur, S. (2017). Transfersomal Phage Cocktail Is an Effective Treatment against Methicillin-Resistant Staphylococcus aureusMediated Skin and Soft Tissue Infections. Antimicrob. Agents Chemother. 61 (10), e02146-16. doi:10.1128/AAC.02146-16

Choińska-Pulit, P. A., Mituła, P., Śliwka, P., Łaba, W., and Skaradzińska, A. (2015). Bacteriophage 501 Encapsulation: Trends and Potential Applications. Trends Food Sci. Technol. 45 (2), 212-221. doi:10.1016/j.tifs.2015.07.001

Chu, L. Y., Utada, A. S., Shah, R. K., Kim, J. W., and Weitz, D. A. (2007). Controllable Monodisperse Multiple Emulsions. Angew. Chem. Int. Ed. Engl. 46 (47), 8970-8974. doi:10.1002/anie.200701358
Cinquerrui, S., Mancuso, F., Vladisavljević, G. T., Bakker, S. E., and Malik, D. J. (2018). Nanoencapsulation of Bacteriophages in Liposomes Prepared Using Microfluidic Hydrodynamic Flow Focusing. Front. Microbiol. 9, 2172. doi:10.3389/fmicb.2018.02172

Clokie, M. R., Millard, A. D., Letarov, A. V., and Heaphy, S. (2011). Phages in Nature. Bacteriophage 1 (1), 31-45. doi:10.4161/bact.1.1.14942

Colom, J., Cano-Sarabia, M., Otero, J., Cortés, P., Maspoch, D., and Llagostera, M. (2015). Liposome-Encapsulated Bacteriophages for Enhanced Oral Phage Therapy against Salmonella Spp. Appl. Environ. Microbiol. 81 (14), 4841-4849. doi:10.1128/AEM.00812-15

Dai, M., Senecal, A., and Nugen, S. R. (2014). Electrospun Water-Soluble Polymer Nanofibers for the Dehydration and Storage of Sensitive Reagents. Nanotechnology 25 (22), 225101. doi:10.1088/0957-4484/25/22/225101

Darwhekar, G., Jain, D. K., and Choudhary, A. (2012). Elastic Liposomes for Delivery of Neomycin Sulphate in Deep Skin Infection. Asian J. Pharm. Sci. 7, 230-240.

Demirci, S., Celebioglu, A., Aytac, Z., and Uyar, T. (2014). pH-Responsive Nanofibers with Controlled Drug Release Properties. Polym. Chem. 5, 2050-2056. doi:10.1039/c3py01276j

Deng, N.-N., Mou, C.-L., Wang, W., Ju, X.-J., Xie, R., and Chu, L.-Y. (2014). Multiple Emulsion Formation from Controllable Drop Pairs in Microfluidics. Microfluid Nanofluid 17, 967-972. doi:10.1007/s10404-014-1381-3

Dickinson, E. (2011). Double Emulsions Stabilized by Food Biopolymers. Food Biophys. 6 (1), 1-11. doi:10.1007/s11483-010-9188-6

Dos Santos, D. M., Correa, D. S., Medeiros, E. S., Oliveira, J. E., and Mattoso, L. H. C. (2020). Advances in Functional Polymer Nanofibers: From Spinning Fabrication Techniques to Recent Biomedical Applications. ACS Appl. Mater. Inter. 12 (41), 45673-45701. doi:10.1021/acsami.0c12410

Drulis-Kawa, Z., Majkowska-Skrobek, G., Maciejewska, B., Delattre, A. S., and Lavigne, R. (2012). Learning from Bacteriophages - Advantages and Limitations of Phage and Phage-Encoded Protein Applications. Curr. Protein Pept. Sci. 13 (8), 699-722. doi:10.2174/138920312804871193

Duncombe, T. A., Tentori, A. M., and Herr, A. E. (2015). Microfluidics: Reframing Biological Enquiry. Nat. Rev. Mol. Cel. Biol. 16, 554-567. doi:10.1038/nrm4041

Duplessis, C. A., Stockelman, M., Hamilton, T., Merril, G., Brownstein, M., BishopLilly, K., et al. (2019). A Case Series of Emergency Investigational New Drug Applications for Bacteriophages Treating Recalcitrant Multi-Drug Resistant Bacterial Infections: Confirmed Safety and a Signal of Efficacy. J. Intensive Crit. Care 5 (2), 11.

Dąbrowska, K. (2019). Phage Therapy: What Factors Shape Phage Pharmacokinetics and Bioavailability? Systematic and Critical Review. Med. Res. Rev. 39 (5), 2000-2025. doi:10.1002/med.21572

Dąbrowska, K., and Abedon, S. T. (2019). Pharmacologically Aware Phage Therapy: Pharmacodynamic and Pharmacokinetic Obstacles to Phage Antibacterial Action in Animal and Human Bodies. Microbiol. Mol. Biol. Rev. 83 (4), 00012-00019. doi:10.1128/MMBR.00012-19

Esteban, P. P., Alves, D. R., Enright, M. C., Bean, J. E., Gaudion, A., Jenkins, A. T., et al. (2014). Enhancement of the Antimicrobial Properties of Bacteriophage- $K$ via Stabilization Using Oil-In-Water Nano-Emulsions. Biotechnol. Prog. 30 (4), 932-944. doi:10.1002/btpr.1898

Ferry, T., Leboucher, G., Fevre, C., Herry, Y., Conrad, A., Josse, J., et al. (2018). Salvage Debridement, Antibiotics and Implant Retention ("DAIR") with Local Injection of a Selected Cocktail of Bacteriophages: Is it an Option for an Elderly Patient with Relapsing Staphylococcus aureus Prosthetic-Joint Infection?. Open Forum Infect. Dis. 5 (11), ofy269. doi:10.1093/ofid/ofy269

Fish, R., Kutter, E., Wheat, G., Blasdel, B., Kutateladze, M., and Kuhl, S. (2016). Bacteriophage Treatment of Intransigent Diabetic Toe Ulcers: a Case Series. J. Wound Care 25 (7), S27-S33. doi:10.12968/jowc.2016.25.Sup7.S27

Fogelman, I., Davey, V., Ochs, H. D., Elashoff, M., Feinberg, M. B., Mican, J., et al. (2000). Evaluation of CD4+ T Cell Function In Vivo in HIV-Infected Patients as Measured by Bacteriophage phiX174 Immunization. J. Infect. Dis. 182, 435-441. doi:10.1086/315739

Franklyne, J., Iyer, S., Ebenazer, L., Mukherjee, A., and Chandrasekaran, N. (2019). Essential Oil Nanoemulsions: Antibacterial Activity in Contaminated Fruit Juices. Int. J. Food Sci. Technol. 54. doi:10.1111/ijfs.14195

Gallet, R., Kannoly, S., and Wang, I. N. (2011). Effects of Bacteriophage Traits on Plaque Formation. BMC Microbiol. 11, 181. doi:10.1186/1471-2180-11-181 
Gondil, V. S., and Chhibber, S. (2021). Bacteriophage and Endolysin Encapsulation Systems: a Promising Strategy to Improve Therapeutic Outcomes. Front. Pharmacol. 12, 675440. doi:10.3389/fphar.2021.675440

González, S., Fernández, L., Gutiérrez, D., Campelo, Rodríguez, A. B. A., Rodríguez, A., and García, P. (2018). Analysis of Different Parameters Affecting Diffusion, Propagation and Survival of Staphylophages in Bacterial Biofilms. Front. Microbiol. 9, 2348. doi:10.3389/fmicb.2018.02348

González-Menéndez, E., Fernández, L., Gutiérrez, D., Pando, D., Martínez, B., Rodríguez, A., et al. (2018). Strategies to Encapsulate the Staphylococcus aureus Bacteriophage phiIPLA-RODI. Viruses 10 (9), 495. doi:10.3390/ v10090495

Gordillo Altamirano, F. L., and Barr, J. J. (2019). Phage Therapy in the Postantibiotic Era. Clin. Microbiol. Rev. 32 (2), 00066-00018. doi:10.1128/ CMR.00066-18

Gugulothu, D., Barhoum, A., Nerella, R., Ajmer, R., and Bechelany, M. (2019). "Fabrication of Nanofibers: Electrospinning and Non-electrospinning Techniques," in Handbook of Nanofibers. Editors A. Barhoum, M. Bechelany, and A. Makhlouf (Cham: Springer). doi:10.1007/978-3-31953655-2_6

Haider, A., Haider, S., and Kang, I.-K. (2018). A Comprehensive Review Summarizing the Effect of Electrospinning Parameters and Potential Applications of Nanofibers in Biomedical and Biotechnology. Arabian J. Chem. 11, 1165-1188. doi:10.1016/j.arabjc.2015.11.015

Harada, L. K., Silva, E. C., Campos, W. F., Del Fiol, F. S., Vila, M., Dąbrowska, K., et al. (2018). Biotechnological Applications of Bacteriophages: State of the Art. Microbiol. Res. 212-213, 38-58. doi:10.1016/j.micres.2018.04.007

Harris, J. M., Martin, N. E., and Modi, M. (2001). PEGylation: A Novel Process for Modifying Pharmacokinetics. Clin. Pharmacokinet. 40, 539-551. doi:10.2165/ 00003088-200140070-00005

Hathaway, H., Ajuebor, J., Stephens, L., Coffey, A., Potter, U., Sutton, J. M., et al. (2016). Thermally Triggered Release of the Bacteriophage Endolysin CHAPK and the Bacteriocin Lysostaphin for the Control of Methicillin Resistant Staphylococcus aureus (MRSA). J. Controlled Release 245, 108-115. doi:10.1016/j.jconrel.2016.11.030

Hathaway, H., Alves, D. R., Bean, J., Esteban, P. P., Ouadi, K., Sutton, J. M., et al. (2015). Poly(N-isopropylacrylamide-co-allylamine) (PNIPAM-Co-ALA) Nanospheres for the Thermally Triggered Release of Bacteriophage K. Eur. J. Pharm. Biopharm. 96, 437-441. doi:10.1016/j.ejpb.2015.09.013

Heskins, M., and Guillet, J. E. (1968). Solution Properties of Poly (N-Isopropylacrylamide). J. Macromolecular Sci. A- Chem. 8, 1441-1455. doi:10.1080/10601326808051910

Hua, S. (2015). Lipid-based Nano-Delivery Systems for Skin Delivery of Drugs and Bioactives. Front. Pharmacol. 6, 219. doi:10.3389/fphar.2015.00219

Huff, W. E., Huff, G. R., Rath, N. C., Balog, J. M., and Donoghue, A. M. (2002). Prevention of Escherichia coli Infection in Broiler Chickens with a Bacteriophage Aerosol spray. Poult. Sci. 81 (10), 1486-1491. doi:10.1093/ps/ 81.10.1486

Huff, W. E., Huff, G. R., Rath, N. C., and Donoghue, A. M. (2010). Immune Interference of Bacteriophage Efficacy when Treating Colibacillosis in Poultry. Poult. Sci. 89, 895-900. doi:10.3382/ps.2009-00528

Huh, H., Wong, S., St Jean, J., and Slavcev, R. (2019). Bacteriophage Interactions with Mammalian Tissue: Therapeutic Applications. Adv. Drug Deliv. Rev. 145, 4-17. doi:10.1016/j.addr.2019.01.003

Hujaya, S. D., Lorite, G. S., Vainio, S. J., and Liimatainen, H. (2018). Polyion Complex Hydrogels from Chemically Modified Cellulose Nanofibrils: Structure-Function Relationship and Potential for Controlled and $\mathrm{pH}-$ Responsive Release of Doxorubicin. Acta Biomater. 75, 346-357. doi:10.1016/j.actbio.2018.06.013

Hyman, P. (2019). Phages for Phage Therapy: Isolation, Characterization, and Host Range Breadth. Pharmaceuticals (Basel) 12 (1), 35. doi:10.3390/ph12010035

Immordino, M. L., Dosio, F., and Cattel, L. (2006). Stealth Liposomes: Review of the Basic Science, Rationale, and Clinical Applications, Existing and Potential. Int. J. Nanomedicine 1 (3), 297-315.

Inchley, C. J. (1969). The Actvity of Mouse Kupffer Cells Following Intravenous Injection of T4 Bacteriophage. Clin. Exp. Immunol. 5 (1), 173-187.

Jault, P., Leclerc, T., Jennes, S., Pirnay, J. P., Que, Y. A., Resch, G., et al. (2019). Efficacy and Tolerability of a Cocktail of Bacteriophages to Treat Burn Wounds Infected by Pseudomonas aeruginosa (PhagoBurn): a Randomised, Controlled,
Double-Blind Phase 1/2 Trial. Lancet Infect. Dis. 19 (1), 35-45. doi:10.1016/ S1473-3099(18)30482-1

Jennes, S., Merabishvili, M., Soentjens, P., Pang, K. W., Rose, T., Keersebilck, E., et al. (2017). Use of Bacteriophages in the Treatment of Colistin-Only-Sensitive Pseudomonas aeruginosa Septicaemia in a Patient with Acute Kidney Injury-A Case Report. Crit. Care 21 (1), 129. doi:10.1186/s13054-017-1709-y

Jin, J. F., Zhu, L. L., Chen, M., Xu, H. M., Wang, H. F., Feng, X. Q., et al. (2015). The Optimal Choice of Medication Administration Route Regarding Intravenous, Intramuscular, and Subcutaneous Injection. Patient Prefer Adherence 9, 923-942. doi:10.2147/PPA.S87271

Kanouni, M., Rosano, H. L., and Naouli, N. (2003). Preparation of a Stable Double Emulsion (W1/O/W2): Role of the Interfacial Films on the Stability of the System. Adv. Colloid Interf. Sci 99, 229-254. doi:10.1016/S0001-8686(02)00079-9

Kasman, L. M., Kasman, A., Westwater, C., Dolan, J., Schmidt, M. G., and Norris, J. S. (2002). Overcoming the Phage Replication Threshold: a Mathematical Model with Implications for Phage Therapy. J. Virol. 76 (11), 5557-5564. doi:10.1128/jvi.76.11.5557-5564.2002:

Kastner, E., Kaur, R., Lowry, D., Moghaddam, B., Wilkinson, A., and Perrie, Y. (2014). High-throughput Manufacturing of Size-Tuned Liposomes by a New Microfluidics Method Using Enhanced Statistical Tools for Characterization. Int. J. Pharm. 477, 361-368. doi:10.1016/j.ijpharm.2014.10.030

Kaur, S., Harjai, K., and Chhibber, S. (2014). Bacteriophage-aided Intracellular Killing of Engulfed Methicillin-Resistant Staphylococcus aureus (MRSA) by Murine Macrophages. Appl. Microbiol. Biotechnol. 98 (10), 4653-4661. doi:10.1007/s00253-014-5643-5

Kaur, S., Harjai, K., and Chhibber, S. (2016). Vivo Assessment of Phage and Linezolid Based Implant Coatings for Treatment of Methicillin Resistant $S$. aureus (MRSA) Mediated Orthopaedic Device Related Infections. PLoS One 11 (6), e0157626. doi:10.1371/journal.pone.0157626

Keller, R., and Zatzman, M. L. (1959). Studies on the Factors Concerned in the Disappearance of Bacteriophage Particles from the Animal Body. J. Immunol. 83 (2), 167-172.

Kenry, L. C. T., and Lim, C. T. (2017). Nanofiber Technology: Current Status and Emerging Developments. Prog. Polym. Sci. 70, 1-17. doi:10.1016/ j.progpolymsci.2017.03.002

Koo, C. K., Senecal, K., Senecal, A., and Nugen, S. R. (2016). Dehydration of Bacteriophages in Electrospun Nanofibers: Effect of Excipients in Polymeric Solutions. Nanotechnology. 27 (48), 485102. doi:10.1088/0957-4484/27/48/ 485102

Korehei, R., and Kadla, J. (2013). Incorporation of T4 Bacteriophage in Electrospun Fibres. J. Appl. Microbiol. 114 (5), 1425-1434. doi:10.1111/jam.12158

Koskella, B., and Brockhurst, M. A. (2014). Bacteria-phage Coevolution as a Driver of Ecological and Evolutionary Processes in Microbial Communities. FEMS Microbiol. Rev. 38 (5), 916-931. doi:10.1111/1574-6976.12072

Kumar, M., Bishnoi, R. S., Shukla, A. K., and Jain, C. P. (2019). Techniques for Formulation of Nanoemulsion Drug Delivery System: A Review. Prev. Nutr. Food Sci. 24 (3), 225-234. doi:10.3746/pnf.2019.24.3.225

Kumari, S., Harjai, K., and Chhibber, S. (2009). Efficacy of Bacteriophage Treatment in Murine Burn Wound Infection Induced by klebsiella Pneumoniae. J. Microbiol. Biotechnol. 19 (6), 622-628. doi:10.4014/jmb.0808.493

Kutter, E., and Sulakvelidze, A. (2005). "Introduction," in Bacteriophages Biology and Applications. Editors E. Kutter and A. Sulakvelidze. (Boca Raton: CRC Press), 1-4. Lamichhane, N., Udayakumar, T. S., D'Souza, W. D., Simone, C. B., Raghavan, S. R., Polf, J., et al. (2018). Liposomes: Clinical Applications and Potential for Image-Guided Drug Delivery. Molecules 23 (2), 288. doi:10.3390/ molecules 23020288

Lebeaux, D., Merabishvili, M., Caudron, E., Lannoy, D., Van Simaey, L., Duyvejonck, H., et al. (2021). A Case of Phage Therapy against PandrugResistant Achromobacter Xylosoxidans in a 12-Year-Old Lung-Transplanted Cystic Fibrosis Patient. Viruses 13 (1), 60. doi:10.3390/v13010060

Lee, S.-W., and Belcher, A. M. (2004). Virus-based Fabrication of Micro- and Nanofibers Using Electrospinning. Nano Lett. 4, 387-390. doi:10.1021/ nl034911t

Leung, S. S. Y., Morales, S., Britton, W., Kutter, E., and Chan, H. K. (2018) Microfluidic-assisted Bacteriophage Encapsulation into Liposomes. Int. J. Pharm. 545 (1-2), 176-182. doi:10.1016/j.ijpharm.2018.04.063

Levin, B. R., and Bull, J. J. (2004). Population and Evolutionary Dynamics of Phage Therapy. Nat. Rev. Microbiol. 2 (2), 166-173. doi:10.1038/nrmicro822 
Leyva-Gómez, G., Piñón-Segundo, E., Mendoza-Muñoz, N., ZambranoZaragoza, M. L., Mendoza-Elvira, S., and Quintanar-Guerrero, D. (2018). Approaches in Polymeric Nanoparticles for Vaginal Drug Delivery: A Review of the State of the Art. Int. J. Mol. Sci. 19 (6), 1549. doi:10.3390/ ijms19061549

Lima, L. H., Morales, Y., and Cabral, T. (2016). Ocular Biocompatibility of Poly-NIsopropylacrylamide (pNIPAM). J. Ophthalmol. 2016, 5356371. doi:10.1155/ 2016/5356371

Lin, D. M., Koskella, B., and Lin, H. C. (2017). Phage Therapy: An Alternative to Antibiotics in the Age of Multi-Drug Resistance. World J. Gastrointest. Pharmacol. Ther. 8 (3), 162-173. doi:10.4292/wjgpt.v8.i3.162

Loc-Carrillo, C., and Abedon, S. T. (2011). Pros and Cons of Phage Therapy. Bacteriophage 1 (2), 111-114. doi:10.4161/bact.1.2.14590

Loh, B., Gondil, V. S., Manohar, P., Khan, F. M., Yang, H., and Leptihn, S. (2020). Encapsulation and Delivery of Therapeutic Phages. Appl. Environ. Microbiol. 87 (5), e01979-20. doi:10.1128/AEM.01979-20

Lombardo, D., Calandra, P., Barreca, D., Magazù, S., and Kiselev, M. A. (2016). Soft Interaction in Liposome Nanocarriers for Therapeutic Drug Delivery. Nanomaterials (Basel) 6 (7), 125. doi:10.3390/nano6070125

Love, M. J., Abeysekera, G. S., Muscroft-Taylor, A. C., Billington, C., and Dobson, R. C. J. (2020). On the Catalytic Mechanism of Bacteriophage Endolysins: Opportunities for Engineering. Biochim. Biophys. Acta Proteins Proteom. 1868 (1), 140302. doi:10.1016/j.bbapap.2019.140302

Lu, Y., Huang, J., Yu, G., Cardenas, R., Wei, S., Wujcik, E. K., et al. (2016). Coaxial Electrospun Fibers: Applications in Drug Delivery and Tissue Engineering. Wiley Interdiscip. Rev. Nanomed. Nanobiotechnol. 8, 654-677. doi:10.1002/ wnan.1391

Majewska, J., Beta, W., Lecion, D., Hodyra-Stefaniak, K., Kłopot, A., Kaźmierczak, Z., et al. (2015). Oral Application of T4 Phage Induces Weak Antibody Production in the Gut and in the Blood. Viruses 7 (8), 4783-4799. doi: $10.3390 / \mathrm{v} 7082845$

Malam, Y., Loizidou, M., and Seifalian, A. M. (2009). Liposomes and Nanoparticles: Nanosized Vehicles for Drug Delivery in Cancer. Trends Pharmacol. Sci. 30 (11), 592-599. doi:10.1016/j.tips.2009.08.004

Malik, D. J., Sokolov, I. J., Vinner, G. K., Mancuso, F., Cinquerrui, S., Vladisavljevic, G. T., et al. (2017). Formulation, Stabilisation and Encapsulation of Bacteriophage for Phage Therapy. Adv. Colloid Interf. Sci. 249, 100-133. doi:10.1016/j.cis.2017.05.014

Mallick, S., and Choi, J. S. (2014). Liposomes: Versatile and Biocompatible Nanovesicles for Efficient Biomolecules Delivery. J. Nanosci Nanotechnol 14, 755-765. doi:10.1166/jnn.2014.9080

Matochko, W. L., Ng, S., Jafari, M. R., Romaniuk, J., Tang, S. K., and Derda, R. (2012). Uniform Amplification of Phage Display Libraries in Monodisperse Emulsions. Methods 58, 18-27. doi:10.1016/j.ymeth.2012.07.012

Mcclements, D. J., and Rao, J. (2011). Food-Grade Nanoemulsions: Formulation, Fabrication, Properties, Performance, Biological Fate, and Potential Toxicity. Crit. Rev. Food Sci. Nutr. 51, 285-330. doi:10.1080/ 10408398.2011.559558

McVay, C. S., Velásquez, M., and Fralick, J. A. (2007). Phage Therapy of Pseudomonas aeruginosa Infection in a Mouse Burn Wound Model. Antimicrob. Agents Chemother. 51 (6), 1934-1938. doi:10.1128/AAC.01028-06

Meers, P., Neville, M., Malinin, V., Scotto, A. W., Sardaryan, G., Kurumunda, R., et al. (2008). Biofilm Penetration, Triggered Release and In Vivo Activity of Inhaled Liposomal Amikacin in Chronic Pseudomonas aeruginosa Lung Infections. J. Antimicrob. Chemother. 61 (4), 859-868. doi:10.1093/jac/ dkn059

Mehta, R., Chawla, A., Sharma, P., and Pawar, P. (2013). Formulation and In Vitro Evaluation of Eudragit S-100 Coated Naproxen Matrix Tablets for colontargeted Drug Delivery System. J. Adv. Pharm. Technol. Res. 4 (1), 31-41. doi:10.4103/2231-4040.107498

Mengistu Lemma, S., Bossard, F., and Rinaudo, M. (2016). Preparation of Pure and Stable Chitosan Nanofibers by Electrospinning in the Presence of Poly(ethylene Oxide). Int. J. Mol. Sci. 17 (11), 1790. doi:10.3390/ ijms 17111790

Monfared, G. S., Ertl, P., and Rothbauer, M. (2020). An On-Chip Wound Healing Assay Fabricated by Xurography for Evaluation of Dermal Fibroblast Cell Migration and Wound Closure. Sci. Rep. 10 (1), 16192-16214. doi:10.1038/ s41598-020-73055-7
Murphy, T. W., Zhang, Q., Naler, L. B., Ma, S., and Lu, C. (2017). Recent Advances in the Use of Microfluidic Technologies for Single Cell Analysis. Analyst 143 (1), 60-80. doi:10.1039/c7an01346a

Najlah, M., Said Suliman, A., Tolaymat, I., Kurusamy, S., Kannappan, V., Elhissi, A. M. A., et al. (2019). Development of Injectable PEGylated Liposome Encapsulating Disulfiram for Colorectal Cancer Treatment. Pharmaceutics 11 (11), 610. doi:10.3390/pharmaceutics 11110610

Navarro, F., and Muniesa, M. (2017). Phages in the Human Body. Front. Microbiol. 8, 566. doi:10.3389/fmicb.2017.00566

Nieth, A., Verseux, C., Barnert, S., Süss, R., and Römer, W. (2015). A First Step toward Liposome-Mediated Intracellular Bacteriophage Therapy. Expert Opin. Drug Deliv. 12 (9), 1411-1424. doi:10.1517/17425247.2015.1043125

Nikam, V., Kotade, K. B., and Gaware, V. M. (2011). Eudragit a Versatile Polymer: A Review. Pharmacologyonline 1, 152-164.

Nilsson, A. S. (2014). Phage Therapy-Cconstraints and Possibilities. Ups. J. Med. Sci. 119 (2), 192-198. doi:10.3109/03009734.2014.902878

Nilsson, A. S. (2019). Pharmacological Limitations of Phage Therapy. Ups. J. Med. Sci. 124 (4), 218-227. doi:10.1080/03009734.2019.1688433

Nir-Paz, R., Gelman, D., Khouri, A., Sisson, B. M., Fackler, J., Alkalay-Oren, S., et al. (2019). Successful Treatment of Antibiotic-Resistant, Poly-Microbial Bone Infection with Bacteriophages and Antibiotics Combination. Clin. Infect. Dis. 69 (11), 2015-2018. doi:10.1093/cid/ciz222

Nogueira, F., Karumidze, N., Kusradze, I., Goderdzishvili, M., Teixeira, P., and Gouveia, I. C. (2017). Immobilization of Bacteriophage in Wound-Dressing Nanostructure. Nanomedicine 13 (8), 2475-2484. doi:10.1016/ j.nano.2017.08.008

Oechslin, F., Piccardi, P., Mancini, S., Gabard, J., Moreillon, P., Entenza, J. M., et al. (2017). Synergistic Interaction between Phage Therapy and Antibiotics Clears Pseudomonas aeruginosa Infection in Endocarditis and Reduces Virulence. J. Infect. Dis. 215 (5), 703-712. doi:10.1093/infdis/jiw632

Otero, J., García-Rodríguez, A., Cano-Sarabia, M., Maspoch, D., Marcos, R., Cortés, P., et al. (2019). Biodistribution of Liposome-Encapsulated Bacteriophages and Their Transcytosis during Oral Phage Therapy. Front. Microbiol. 10, 689. doi:10.3389/fmicb.2019.00689

Pal, K., Rahier, H., Uludag, H., Kim, I., and Bechelany, M. (2019). Nanofibers as New-Generation Materials: From Spinning and Nano-Spinning Fabrication Techniques to Emerging Applications. Appl. Mater. Today 17, 1-35. doi:10.1016/j.apmt.2019.06.015

Palleria, C., Di Paolo, A., Giofrè, C., Caglioti, C., Leuzzi, G., Siniscalchi, A., et al. (2013). Pharmacokinetic Drug-Drug Interaction and Their Implication in Clinical Management. J. Res. Med. Sci. 18 (7), 601-610.

Payne, R. J., and Jansen, V. A. (2001). Understanding Bacteriophage Therapy as a Density-dependent Kinetic Process. J. Theor. Biol. 208 (1), 37-48. doi:10.1006/ jtbi.2000.2198

Payne, R. J., and Jansen, V. A. (2003). Pharmacokinetic Principles of Bacteriophage Therapy. Clin. Pharmacokinet. 42 (4), 315-325. doi:10.2165/00003088200342040-00002

Payne, R. J., Phil, D., and Jansen, V. A. (2000). Phage Therapy: the peculiar Kinetics of Self-Replicating Pharmaceuticals. Clin. Pharmacol. Ther. 68 (3), 225-230. doi:10.1067/mcp.2000.109520

Philipson, C. W., Voegtly, L. J., Lueder, M. R., Long, K. A., Rice, G. K., Frey, K. G., et al. (2018). Characterizing Phage Genomes for Therapeutic Applications. Viruses 10 (4), 188. doi:10.3390/v10040188

Pierre, M. B., and Dos Santos Miranda Costa, I. (2011). Liposomal Systems as Drug Delivery Vehicles for Dermal and Transdermal Applications. Arch. Dermatol. Res. 303 (9), 607-621. doi:10.1007/s00403-011-1166-4

Portilla, S., Fernández, L., Gutiérrez, D., Rodríguez, A., and García, P. (2020). Encapsulation of the Antistaphylococcal Endolysin LysRODI in pH-Sensitive Liposomes. Antibiotics (Basel) 9 (5), 242. doi:10.3390/antibiotics9050242

Potrč, T., Baumgartner, S., Roškar, R., Planinšek, O., Lavrič, Z., Kristl, J., et al. (2015). Electrospun Polycaprolactone Nanofibers as a Potential Oromucosal Delivery System for Poorly Water-Soluble Drugs. Eur. J. Pharm. Sci. 75, 101-113. doi:10.1016/j.ejps.2015.04.004

Principi, N., Silvestri, E., and Esposito, S. (2019). Advantages and Limitations of Bacteriophages for the Treatment of Bacterial Infections. Front. Pharmacol. 10, 513. doi:10.3389/fphar.2019.00513

Puri, A., Loomis, K., Smith, B., Lee, J. H., Yavlovich, A., Heldman, E., et al. (2009). Lipid-based Nanoparticles as Pharmaceutical Drug Carriers: from Concepts to 
Clinic. Crit. Rev. Ther. Drug Carrier Syst. 26 (6), 523-580. doi:10.1615/ critrevtherdrugcarriersyst.v26.i6.10

Ran, R., Sun, Q., Baby, T., Wibowo, D., Middelberg, A. P. J., and Zhao, C.-X. (2017). Multiphase Microfluidic Synthesis of Micro- and Nanostructures for Pharmaceutical Applications. Chem. Eng. Sci. 169, 78-96. doi:10.1016/ j.ces.2017.01.008

Rios, A., Vila, M., Lima, R., Del Fiol, F., Tubino, M., Teixeira, J., et al. (2017). Structural and Functional Stabilization of Bacteriophage Particles within the Aqueous Core of a W/O/W Multiple Emulsion: A Potential Biotherapeutic System for the Inhalational Treatment of Bacterial Pneumonia. Process Biochem. 64, 177-192. doi:10.1016/ j.procbio.2017.09.022

Ryan, E. M., Gorman, S. P., Donnelly, R. F., and Gilmore, B. F. (2011). Recent Advances in Bacteriophage Therapy: How Delivery Routes, Formulation, Concentration and Timing Influence the success of Phage Therapy. J. Pharm. Pharmacol. 63 (10), 1253-1264. doi:10.1111/j.2042-7158.2011.01324.x

Sachan, R., Parashar, T., and Singh, V. (2013). Drug Carrier Transfersomes: a Novel Tool for Transdermal Drug Delivery System. Int. J. Res. Dev. Pharm. L. Sci. 2, 309-316.

Salalha, W., Kuhn, J., Dror, Y., and Zussman, E. (2006). Encapsulation of Bacteria and Viruses in Electrospun Nanofibres. Nanotechnology 17, 4675-4681. doi:10.1088/0957-4484/17/18/025

Salmaso, S., and Caliceti, P. (2013). Stealth Properties to Improve Therapeutic Efficacy of Drug Nanocarriers. J. Drug Deliv. 2013, 374252. doi:10.1155/2013/ 374252

Sarhan, W. A., and Azzazy, H. M. (2017). Apitherapeutics and Phage-Loaded Nanofibers as Wound Dressings with Enhanced Wound Healing and Antibacterial Activity. Nanomedicine (Lond) 12 (17), 2055-2067. doi:10.2217/nnm-2017-0151

Sarker, S. A., Sultana, S., Reuteler, G., Moine, D., Descombes, P., Charton, F., et al. (2016). Oral Phage Therapy of Acute Bacterial Diarrhea with Two Coliphage Preparations: A Randomized Trial in Children from Bangladesh. EBioMedicine 4, 124-137. doi:10.1016/j.ebiom.2015.12.023

Sawant, K. K, Mundada, V. P., and Patel, V. J. (2017). Development and Optimization of W/o/w Multiple Emulsion of Lisinopril Dihydrate Using Plackett Burman and Box-Behnken Designs. J. Nanomed. Nanotechnol. 08, 422. doi:10.4172/2157-7439.1000422

Sawant, R. R., and Torchilin, V. P. (2012). Challenges in Development of Targeted Liposomal Therapeutics. AAPS J. 14 (2), 303-315. doi:10.1208/s12248-0129330-0

Schmelcher, M., Donovan, D. M., and Loessner, M. J. (2012). Bacteriophage Endolysins as Novel Antimicrobials. Future Microbiol. 7 (10), 1147-1171. doi: $10.2217 / \mathrm{fmb} .12 .97$

Schultz, I., and Frohlich, E. (1965). Viruria and Viraliquoria in the Dog after Intravenous Injection of T5 Bacteriophage. Proc. Soc. Exp. Biol. Med. 118, 136-138. doi:10.3181/00379727-118-29778

Shahriar, S. M. S., Mondal, J., Hasan, M. N., Revuri, V., Lee, D. Y., and Lee, Y. K. (2019). Electrospinning Nanofibers for Therapeutics Delivery. Nanomaterials (Basel) 9 (4), 532. doi:10.3390/nano9040532

Sharma, S., Chatterjee, S., Datta, S., Prasad, R., Dubey, D., Prasad, R. K., et al. (2017). Bacteriophages and its Applications: an Overview. Folia Microbiol. (Praha) 62 (1), 17-55. doi:10.1007/s12223-016-0471-x

Silva, M. D., Paris, J. L., Gama, F. M., Silva, B. F. B., and Sillankorva, S. (2021). Sustained Release of a Streptococcus pneumoniae Endolysin from Liposomes for Potential Otitis media Treatment. ACS Infect. Dis. 7 (8), 2127-2137. doi:10.1021/acsinfecdis.1c00108

Simmons, M., Drescher, K., Nadell, C. D., and Bucci, V. (2018). Phage Mobility Is a Core Determinant of Phage-Bacteria Coexistence in Biofilms. ISME J. 12 (2), 531-543. doi:10.1038/ismej.2017.190

Singh, P., Magalhães, S., Alves, L., Antunes, F., Miguel, M., Lindman, B., et al. (2018). Cellulose-based Edible Films for Probiotic Entrapment. Food Hydrocolloids 88, 68-74. doi:10.1016/j.foodhyd.2018.08.057

Singla, S., Harjai, K., Katare, O. P., and Chhibber, S. (2015). Bacteriophage-loaded Nanostructured Lipid Carrier: Improved Pharmacokinetics Mediates Effective Resolution of Klebsiella Pneumoniae-Induced Lobar Pneumonia. J. Infect. Dis. 212 (2), 325-334. doi:10.1093/infdis/jiv029

Singla, S., Harjai, K., Katare, O. P., and Chhibber, S. (2016). Encapsulation of Bacteriophage in Liposome Accentuates its Entry in to Macrophage and Shields it from Neutralizing Antibodies. PLoS One 11 (4), e0153777. doi:10.1371/ journal.pone.0153777

Slopek, S., Weber-Dabrowska, B., Dabrowski, M., and Kucharewicz-Krukowska, A. (1987). Results of Bacteriophage Treatment of Suppurative Bacterial Infections in the Years 1981-1986. Arch. Immunol. Ther. Exp. (Warsz) 35 (5), 569-583. Sulakvelidze, A., Alavidze, Z., and Morris, J. G. (2001). Bacteriophage Therapy. Antimicrob. Agents Chemother. 45 (3), 649-659. doi:10.1128/AAC.45.3.649-659.2001

Sulkin, S. E., Finkelstein, R. A., and Rosenblum, E. D. (1957). Effect of Zymosan on Bacteriophage Clearance. Science 125 (3251), 742-743. doi:10.1126/ science.125.3251.742

Tadros, T., Izquierdo, P., Esquena, J., and Solans, C. (2004). Formation and Stability of Nano-Emulsions. Adv. Colloid Interf. Sci. 108-109, 303-318. doi:10.1016/j.cis.2003.10.023

Takemura-Uchiyama, I., Uchiyama, J., Osanai, M., Morimoto, N., Asagiri, T., Ujihara, T., et al. (2014). Experimental Phage Therapy against Lethal LungDerived Septicemia Caused by Staphylococcus aureus in Mice. Microbes Infect. 16 (6), 512-517. doi:10.1016/j.micinf.2014.02.011

Takeuchi, H., Matsui, Y., Sugihara, H., Yamamoto, H., and Kawashima, Y. (2005). Effectiveness of Submicron-Sized, Chitosan-Coated Liposomes in Oral Administration of Peptide Drugs. Int. J. Pharm. 303 (1-2), 160-170. doi:10.1016/j.ijpharm.2005.06.028

Taneja, N., Sethi, S., Tahlan, A., and Kumar, Y. (2019). Introductory Chapter: Stepping into the Post-Antibiotic Era-Challenges and Solutions UK: InTechOpen.

Teo, W. E., and Ramakrishna, S. (2006). A Review on Electrospinning Design and Nanofibre Assemblies. Nanotechnology 17 (14), R89-R106. doi:10.1088/09574484/17/14/R01

Thakral, S., Thakral, N. K., and Majumdar, D. K. (2013). Eudragit: a Technology Evaluation. Expert Opin. Drug Deliv. 10 (1), 131-149. doi:10.1517/ 17425247.2013.736962

Torres-Martinez, E. J., Cornejo Bravo, J. M., Pérez González, G. L., Villarreal Gómez, L. J., and Villarreal Gómez, L. J (2018). A Summary of Electrospun Nanofibers as Drug Delivery System: Drugs Loaded and Biopolymers Used as Matrices. Curr. Drug Deliv. 15 (10), 1360-1374. doi:10.2174/1567201815666180723114326

Tsonos, J., Vandenheuvel, D., Briers, Y., De Greve, H., Hernalsteens, J. P., and Lavigne, R. (2014). Hurdles in Bacteriophage Therapy: Deconstructing the Parameters. Vet. Microbiol. 171 (3-4), 460-469. doi:10.1016/j.vetmic.2013.11.001

Uhr, J. W., Finkelstein, M. S., and Baumann, J. B. (1962). Antibody Formation. III. The Primary and Secondary Antibody Response to Bacteriophage Phi X 174 in guinea Pigs. J. Exp. Med. 115 (3), 655-670. doi:10.1084/jem.115.3.655

van Swaay, D., and deMello, A. (2013). Microfluidic Methods for Forming Liposomes. Lab. Chip 13, 752. doi:10.1039/c2lc41121k

Ventola, C. L. (2015). The Antibiotic Resistance Crisis: Part 1: Causes and Threats. P T 40 (4), 277-283.

Vibhooti, P., Rajan, G., Bisht, S., and Preeti, K. (2013). Preparation and Comparative Characterization of Drug Release from Two Different Chronotherapeutic Drug Delivery Systems of Salbutomol for Nocturnal Asthma. Int. J. Res. Develop. Pharm. Life Sci. 3 (1), 762-772.

Vinner, G. K., and Malik, D. J. (2018). High Precision Microfluidic Microencapsulation of Bacteriophages for Enteric Delivery. Res. Microbiol. 169 (9), 522-530. Available at: https://hdl.handle.net/2134/33924. doi:10.1016/ j.resmic.2018.05.011

Vinner, G. K., Richards, K., Leppanen, M., Sagona, A. P., and Malik, D. J. (2019). Microencapsulation of Enteric Bacteriophages in a $\mathrm{pH}$-Responsive Solid Oral Dosage Formulation Using a Scalable Membrane Emulsification Process. Pharmaceutics 11 (9), 475. doi:10.3390/pharmaceutics11090475

Vinner, G. K., Vladisavljević, G. T., Clokie, M. R. J., and Malik, D. J. (2017). Microencapsulation of Clostridium difficile Specific Bacteriophages Using Microfluidic Glass Capillary Devices for colon Delivery Using pH Triggered Release. PLoS One 12 (10), e0186239. doi:10.1371/journal.pone.0186239

Vladisavljević, G. T., Al Nuumani, R., and Nabavi, S. A. (2017). Microfluidic Production of Multiple Emulsions. Micromachines (Basel) 8 (3), 75 doi:10.3390/mi8030075

Wagner, A., and Vorauer-Uhl, K. (2011). Liposome Technology for Industrial Purposes. J. Drug Deliv. 2011, 591325. doi:10.1155/2011/591325

Walve, J. R., Bakliwal, S. R., Rane, B., and Pawar, S. P. (2011). Transfersomes: A Surrogated Carrier for Transdermal Drug Delivery System. Int. J. Appl. Biol. Pharm. Technol. 2, 204-213. 
Wang, W., Xie, R., Ju, X. J., Luo, T., Liu, L., Weitz, D. A., et al. (2011). Controllable Microfluidic Production of Multicomponent Multiple Emulsions. Lab. Chip 11, 1587-1592. doi:10.1039/c1lc20065h

Wang, X., Piao, Y., Su, Y., and Wang, W. (2018). Driving and Sorting of the Fluorescent Droplets on Digital Microfluidic Platform. Microfluid Nanofluid 22, 129. doi:10.1007/s10404-018-2154-1

Webber, M. J. (2016). Engineering Responsive Supramolecular Biomaterials: Toward Smart Therapeutics. Bioeng. Transl. Med. 1 (3), 252-266. doi:10.1002/btm2.10031

Wells, C. M., Harris, M., Choi, L., Murali, V. P., Guerra, F. D., and Jennings, J. A. (2019). Stimuli-Responsive Drug Release from Smart Polymers. J. Funct. Biomater. 10 (3), 34. doi:10.3390/jfb10030034

Wright, A., Hawkins, C. H., Anggård, E. E., and Harper, D. R. (2009). A Controlled Clinical Trial of a Therapeutic Bacteriophage Preparation in Chronic Otitis Due to Antibiotic-Resistant Pseudomonas aeruginosa; a Preliminary Report of Efficacy. Clin. Otolaryngol. 34 (4), 349-357. doi:10.1111/j.1749-4486.2009.01973.x

Xue, J., Wu, T., Dai, Y., and Xia, Y. (2019). Electrospinning and Electrospun Nanofibers: Methods, Materials, and Applications. Chem. Rev. 119 (8), 5298-5415. doi:10.1021/acs.chemrev.8b00593

Yew, C. H. T., Azari, P., Choi, J. R., Muhamad, F., and Pingguan-Murphy, B. (2018). Electrospun Polycaprolactone Nanofibers as a Reaction Membrane for Lateral Flow Assay. Polymers (Basel) 10 (12), 1387. doi:10.3390/polym10121387

Yin, S., Huang, G., Zhang, Y., Jiang, B., Yang, Z., Dong, Z., et al. (2017). Phage Abp1 Rescues Human Cells and Mice from Infection by Pan-Drug Resistant Acinetobacter Baumannii. Cell Physiol. Biochem. 44 (6), 2337-2345. doi:10.1159/000486117

Young, R., and Gill, J. J. (2015). MICROBIOLOGY. Phage Therapy Redux--What Is to Be Done? Science 350 (6265), 1163-1164. doi:10.1126/science.aad6791
Zhao, C. X. (2013). Multiphase Flow Microfluidics for the Production of Single or Multiple Emulsions for Drug Delivery. Adv. Drug Deliv. Rev. 65 (11-12), 1420-1446. doi:10.1016/j.addr.2013.05.009

Zucca, M., and Savoia, D. (2010). The post-antibiotic Era: Promising Developments in the Therapy of Infectious Diseases. Int. J. Biomed. Sci. 6 (2), 77-86.

Łusiak-Szelachowska, M., Zaczek, M., Weber-Dąbrowska, B., Międzybrodzki, R., Kłak, M., Fortuna, W., et al. (2014). Phage Neutralization by Sera of Patients Receiving Phage Therapy. Viral Immunol. 27 (6), 295-304. doi:10.1089/vim.2013.0128

Conflict of Interest: The authors declare that the research was conducted in the absence of any commercial or financial relationships that could be construed as a potential conflict of interest.

Publisher's Note: All claims expressed in this article are solely those of the authors and do not necessarily represent those of their affiliated organizations, or those of the publisher, the editors and the reviewers. Any product that may be evaluated in this article, or claim that may be made by its manufacturer, is not guaranteed or endorsed by the publisher.

Copyright (c) 2021 Kaur, Kumari, Kumari Negi, Galav, Thakur, Agrawal and Sharma. This is an open-access article distributed under the terms of the Creative Commons Attribution License (CC BY). The use, distribution or reproduction in other forums is permitted, provided the original author(s) and the copyright owner(s) are credited and that the original publication in this journal is cited, in accordance with accepted academic practice. No use, distribution or reproduction is permitted which does not comply with these terms. 